University of Nebraska - Lincoln

DigitalCommons@University of Nebraska - Lincoln

Public Access Theses and Dissertations from

Education and Human Sciences, College of

the College of Education and Human Sciences

8-2011

\title{
Prosocial Behavior as a Protective Factor for Children's Peer Victimization
}

Emily R. Griese

University of Nebraska-Lincoln, emily.griese@huskers.unl.edu

Follow this and additional works at: https://digitalcommons.unl.edu/cehsdiss

Part of the Developmental Psychology Commons, and the Educational Psychology Commons

Griese, Emily R., "Prosocial Behavior as a Protective Factor for Children's Peer Victimization" (2011). Public Access Theses and Dissertations from the College of Education and Human Sciences. 115. https://digitalcommons.unl.edu/cehsdiss/115

This Article is brought to you for free and open access by the Education and Human Sciences, College of (CEHS) at DigitalCommons@University of Nebraska - Lincoln. It has been accepted for inclusion in Public Access Theses and Dissertations from the College of Education and Human Sciences by an authorized administrator of DigitalCommons@University of Nebraska - Lincoln. 


\title{
PROSOCIAL BEHAVIOR AS A PROTECTIVE FACTOR FOR CHILDREN'S PEER VICTIMIZATION
}

\author{
By
}

\author{
Emily R.M. Griese
}

\begin{abstract}
A THESIS
Presented to the Faculty of

The Graduate College at the University of Nebraska

In Partial Fulfillment of Requirements

For the Degree of Master of Arts
\end{abstract}

Major: Educational Psychology

Under the supervision of Professor Eric Buhs

Lincoln, Nebraska

August, 2011 


\title{
PROSOCIAL BEHAVIOR AS A PROTECTIVE FACTOR FOR CHILDREN'S
}

\author{
PEER VICTIMIZATION \\ Emily Rae Griese, M.A. \\ University of Nebraska, 2011
}

Adviser: Eric S. Buhs

The purpose of this study was to investigate the protective role prosocial behaviors may serve for victimized children. Although a significant portion of the victimization literature focuses on the association of victimization with negative outcomes, research findings suggest a need to examine the heterogeneity also apparent in children's responses to victimization. By beginning to examine the variability in children's responses to peer victimization, researchers can gain insight into the dynamic process of peer victimization and begin to define what factors might distinguish children who show resiliency to negative effects from victimization from those who do not. Research examining the protective role a child's behavior, in particular their prosocial behavior, may have for victimized children and their adjustment outcome is needed.

A moderation model was used to test the interaction of peer-nominated prosocial behavior and victimization on self-reported loneliness one year later among a sample of fourth and fifth grade students. A self-report measure of perceived social support was also controlled for in the model. The overall model examined the interaction of prosocial behavior by total victimization as well as by form of victimization (relational and overt). Models were further examined by gender groups.

Results indicated that a child's prosocial behavior moderated the relationship between victimization and loneliness even after controlling for a child's perceived social 
support from peers. Further, when examining specific forms of victimization, relational victimization was the only form significantly moderated by prosocial behavior. These findings were present for both boys and girls. Follow-up plots further indicated that children at the highest level of victimization who were prosocial reported significantly less loneliness than children at high levels of victimization who were not prosocial. Implications for prosocial behaviors as a protective factor for victimized children are discussed. 
Table of Contents

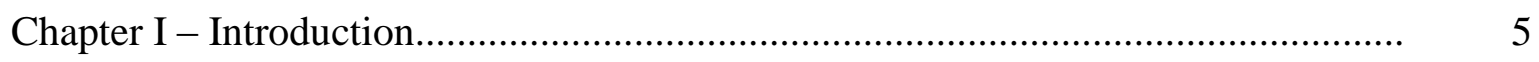

Peer Victimization \& Adjustment Outcomes........................................... $\quad 5$

Prosocial Behaviors............................................. 7

A Theoretical Framework.......................................... 8

The Current Study .............................................. 10

Chapter II - Literature Review..................................... 13

Peer Victimization............................................... 13

Defining Peer Victimization............................... 13

Forms of Peer Victimization.............................. 15

Influences on Peer Victimization........................... 16

Loneliness..................................................... 18

Prosocial Behaviors.............................................. 20

Development of Prosocial Behavior.......................... 20

Prosocial Behavior as a Protective Factor..................... 22

Prosocial Behaviors as a Coping Strategy........................ 24

Type of Coping Strategy.............................. 25

Gender Differences in Coping........................................ 26

The Role of Emotional Regulation........................... 28

The Current Model................................................ 31

Prosocial Peer Support..................................... 33

Necessary Level of Prosociality............................. 35

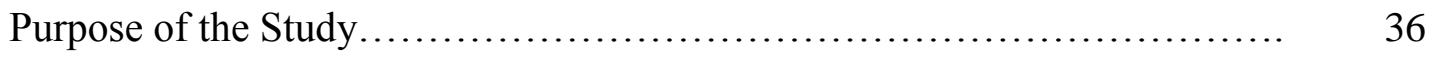

Chapter III - Methods................................................ 38

Participants.................................................... 38 
Procedures......................................................... 38

Measures........................................................... 38

Victimization: Peer-report................................... 38

Prosocial Behaviors: Peer-report.................................... $\quad 39$

Social Support: Self-report.................................... $\quad 39$

Loneliness: Self-report...................................... $\quad 39$

Chapter IV - Results..................................................... 41

Descriptive Statistics............................................. 41

Plan for Data Analysis............................................... 41

Structural Equation Model Testing for Moderation......................... 43

Structural Equation Model Testing for Moderation by Gender Groups......... 46

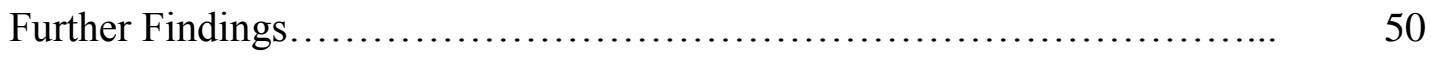

Follow Up Plots................................................... 50

Chapter V - Discussion................................................... 53

Prosocial Behavior as a Moderator.................................... 53

Form of Victimization and Gender.................................... 55

Limitations and Implications for Future Research........................ $\quad 57$

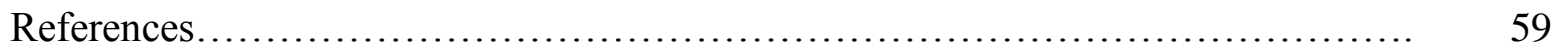

Appendix A............................................................... 73

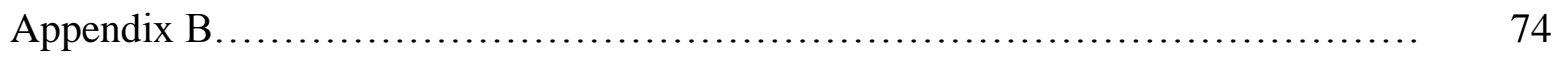

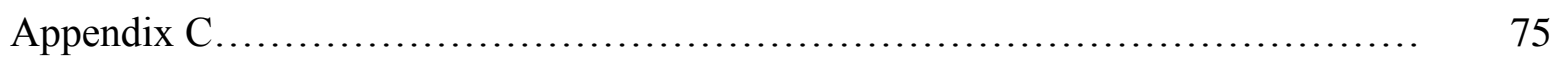

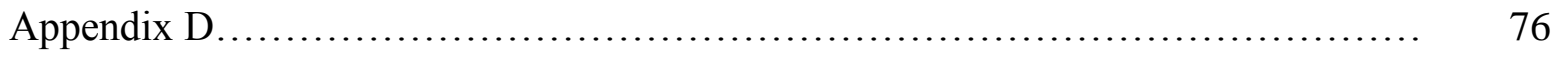

Appendix E............................................................. 77 


\section{Chapter I: Introduction}

It is evident that peer relationships play a central role in the lives of children (Bigelow, Tesson, \& Lewko, 1996; Coleman \& Byrd, 2003), a role that may provide either positive or negative influences on children's social and emotional development. Although researchers are aware of both the positive and negative aspects of children's peer relationships, a majority of the research continues to focus on the negative influences and its maladaptive effects on development (e.g. victimization). Although it is important to understand potentially negative impacts of peer relationships and their effect on children's development, understanding what behaviors a child can engage in to protect against these negative effects is potentially equally salient.

\section{Peer Victimization and Adjustment Outcomes}

One area in particular, peer victimization, has often been examined in light of the negative consequences it may elicit in a child's developmental process. Peer victimization, defined as the repeated negative actions directed toward a child by his or her peers (Crick \& Grotpeter, 1996; Olweus, 1993), has been linked with increases in both short and long term adjustment problems (Boivin \& Hymel, 1997; Buhs, Ladd, \& Herald, 2006). More specifically, peer victimization has been associated with increased internalizing problems such as depression, anxiety, and loneliness along with externalizing problems such as aggression (Boivin, Hymel, \& Hodges, 2001; Kochenderfer-Ladd \& Ladd, 2001). Researchers within the field of peer victimization have indicated that of the internalizing symptoms seen amongst victimized children, loneliness is the most consistent correlate of victimization (Kochenderfer-Ladd \& Wardrop, 2001). 
Victimization and loneliness are often linked because of their shared association with social relationship deficits. For example, loneliness is often negatively related to active participation in social and academic activities (Parkhurst \& Asher, 1992) and positively associated with rejection from peers, increased social stress, and negative affect (Hymel, Rubin, Rowden, \& LeMare, 1990). As victimized children withdraw from peers either because of fear or mistrust, their loneliness begins to increase. These patterns drawn from previous findings indicate that loneliness may emerge in response to victimization through a complex series of interactions that occur over time. It is evident that studying the detrimental effects of peer victimization, particularly in terms of its association with loneliness, is important.

Yet, there are research findings that suggest these negative outcomes are not the only outcomes seen amongst victimized children. A recent call by peer victimization researchers suggests that those in the field should begin to focus on the variations in children's responses to peer victimization and what factors may serve to protect these children from its negative outcomes (see Kochenderfer-Ladd \& Ladd, 2001). In a recent study of middle and high school students evaluating their victimization experiences throughout school, findings indicated that although a significant number of students report being victimized at some point in school (nearly $76.8 \%$ ), only about $14 \%$ estimated significant trauma affecting their social and academic outcomes (Hoover, Oliver, \& Hazler, 1992). These findings shed light on the need to not only study children who report negative effects from victimization, but the need to study those who report little to no negative effects from victimization. Provided the percentage of students indicating little to no effects, researchers are left to consider what factors may be 
protecting these students from the negative effects of peer victimization. By beginning to examine the variability in children's responses to peer victimization, researchers can gain insight into the dynamic process of peer victimization and begin to define what factors might distinguish children who show resiliency to negative effects from victimization from those who do not.

\section{Prosocial Behaviors}

One area of peer relationships research that has focused on the positive developmental outcomes it elicits are examinations of prosocial behaviors. Previous research examining prosocial behavior and peer relationships has primarily focused on the receipt of prosocial acts from peers and its effect on developmental outcomes. The receipt of prosocial behaviors, or prosocial support from peers, has been recognized as a protective factor against the effects of peer victimization on a child's subsequent adjustment (Martin \& Huebner, 2007). In a study examining the associations between prosocial support, peer victimization, and loneliness, researchers found that the effect of peer victimization on loneliness was moderated by prosocial support from peers (Storch $\&$ Masia, 2001). That is, children who were overtly or relationally victimized yet received prosocial support from peers were significantly less lonely than those who were victimized and received no prosocial support from peers.

These findings suggest that receiving prosocial support serves as an important protective factor for victimized children. Further, research continues to point out that prosocial interactions allow children to build self-esteem, to gain emotional support, and to implement effective social skills (Hodges et al., 1999); peer interactions that are likely to decrease the negative effects of peer victimization. Although researchers have begun 
to understand the positive developmental effects of prosocial support, the research has been limited within this area. In particular, although prosocial support from peers has been examined in the victimization-adjustment models, the potential impact of children's own prosocial behavioral tendencies, to our knowledge, have not yet been explored in these models.

Prosocial behavior has been linked with a variety of positive psychosocial indices including adequate social competence with peers, increased perspective taking and interactional skills, adequate conflict resolution, and increased levels of empathy and emotional regulation (Eisenberg \& Fabes, 1998; Eisenberg, Fabes, \& Spinard, 2006). Although researchers are aware of the positive outcomes of prosocial behaviors, its potentially unique role for victimized children remains unexamined. Given the current research on prosocial support and its protective role for victimized children, it seems likely that a child's prosocial behavioral tendency would also serve as a protective factor against the negative adjustment outcomes often associated with peer victimization.

\section{A Theoretical Framework}

Along with the lack of empirical research examining a child's prosocial behavioral tendencies within the victimization-adjustment models, the theoretical framework for understanding these associations is also limited. Researchers interested in the heterogeneity in children's responses to victimization suggest that the way children appraise and manage a stressful event (i.e. victimization) may provide a clearer understanding of why these adjustment differences occur (Kochenderfer-Ladd \& Skinner, 2001). Further, several of the factors associated with appropriate coping strategies such as emotional regulation, perspective taking, \& moral reasoning are also predictive of 
increased levels of prosocial behavior (Eisenberg et al., 2006). Thus, examining prosocial behavior as a potential coping strategy for victimized children is pertinent to the current study.

Further, in examining coping strategies associated with victimization, the process of emotional regulation has surfaced as an important correlate for understanding the variations in children's coping when faced with similar victimization experiences (Goodman \& Sotham-Gerow, 2010). A growing number of research studies lend support to the notion of emotional regulation as a critical component in children's interactions with peers. How children interact with peers requires not only dealing with one's own emotional reactions, but also understanding and reacting to the emotions of others (Eisenberg \& Fabes, 1992). For some victimized children, the continued stress and negative emotions associated with victimization experiences has been found to, over time, diminish their ability to control emotions and adequately cope with the situation. This process of diminished emotional regulation and less adequate coping may subsequently leave victimized children at an increased risk for negative adjustment outcomes (McLaughlin et al., 2009; Southam-Gerow \& Kendall, 2000). For example, victimized children with low levels of emotional regulation and coping abilities have been found to have increased levels of loneliness.

Yet, prior findings reported above indicated these outcomes are not representative of all victimized children. Some children appear more resilient to the stress of victimization and are able to engage in appropriate emotional regulation leading to more adaptive coping strategies. For these children, their coping may take the form of increased prosocial behavior toward peers. For example, prior research findings suggest 
that appropriate emotional and behavioral regulation is positively related to the development of prosocial behaviors (Eisenberg, Fabes, Guthrie, \& Reiser, 2000). Further, children rated higher in emotional regulation skills are found to be more likely to engage in socially appropriate behaviors and have a higher capacity for empathy. Conversely, children with lower emotional regulation skills and coping abilities were found to have higher levels of internalizing symptoms (Langrock et al., 2002; Wadsworth \& Compas, 2000).

These findings suggest that if children are able to regulate their emotions in the face of victimization, they are more likely to cope with the situation through appropriate, positive social behaviors (e.g. prosocial behaviors). Further, prior findings have indicated that the pursuit of prosocial goals and behaviors is negatively associated with loneliness (Gable, 2006). Thus, it appears that for children who are victimized by peers, having a prosocial behavioral tendency that increases social engagement may serve as a protective factor against loneliness. Understanding this process and the potential role prosocial behaviors have in the victimization-loneliness model is pertinent to the current study.

\section{The Current Study}

The primary goal of the current study is to examine the potential moderating role of prosocial behavior in the relationship between peer victimization and loneliness. This goal is based on the need for further examination into this particular model given the deficiencies within the current literature. The provided theoretical framework suggests prosocial behavior may function as a protective factor for victimized children and in particular may help diminish one of the most salient negative social outcomes of 
victimization, loneliness. Thus, it is hypothesized that victimized children with higher levels of prosocial behavior relative to their peers (see Vitaro et al, 1990) will report significantly less loneliness than those who are victimized yet show lower levels of prosocial behavior.

Further, it is important that the current study examine whether or not prosocial behavior uniquely moderators this relationship above and beyond the receipt of prosocial support from peers. Few if any studies have examined prosocial behavior independent of prosocial support from peers in the victimization-adjustment model. Although there is evident overlap in the positive outcomes associated with both the receipt of and engagement in prosocial behaviors (Eisenberg et al., 2006), it is important to also understand these effects apart from one another. Perceived social support from peers will be controlled for within the model (see Figure 1).

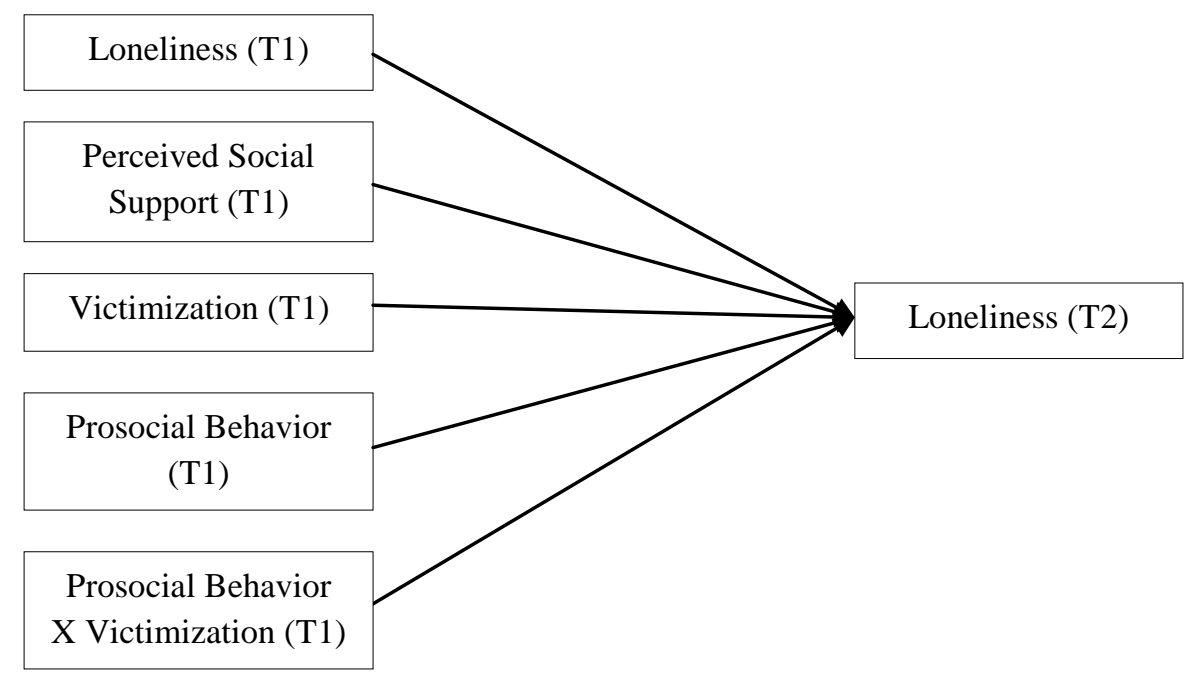

Figure 1. Proposed moderation model. 
A second goal of the current study is to examine the specific forms of victimization within the proposed model. The two forms of victimization most salient in the current research, relational and overt, have been found to lead to different, yet often overlapping outcomes. Relational victimization is defined as behaviors that damage the child's social relations (e.g. gossiping, spreading rumors, and social exclusion). The social exclusion associated with relational victimization has been found to increase the likelihood of negative psychosocial maladjustment, including concurrent loneliness and lowered self-esteem (Prinstein, Boergers, \& Vernberg, 2001). Overt victimization (physical and verbal victimization often demonstrated by kicking, hitting, and namecalling), on the other hand, has been found to lead to increased negative adjustment outcomes such as higher levels of aggression and depression. Although research studies suggest that the specific form of victimization the child endures is an important factor in the level and type of maladjustment that occurs (Roecker Phelps, 2001), examining the effects of prosocial behaviors as a potential protective factor for these effects remains unexamined.

Finally, given prior research findings suggesting the association of gender and form of victimization (Crick \& Grotpeter, 1996), an important aspect of this study is to examine potential gender effects. Findings suggest that in general, girls are more likely to experience relational victimization while boys are more likely to experience overt victimization. Examining the form of victimization's potential links to gender and their association with a child's prosocial behavior is also a central aspect of the current model. These links have not been thoroughly examined and a goal of the current study is to provide an initial exploration of these factors within the current model. 


\section{Chapter II: Literature Review}

The following literature review will examine the theoretical and empirical support for the contention that prosocial behaviors function as a protective factor for victimized children. These associations will be explored first by defining and discussing peer victimization along with its variations in terms of form and gender. Next, the relationship between peer victimization and loneliness will be examined. Finally, prosocial behaviors will be defined and explored theoretically as a type of coping strategy for victimized children. In examining coping strategies and emotional regulation as part of the complex process of prosocial behavior development, we hope to better understand and answer the question of what role prosocial behaviors serve for victimized children.

\section{Peer Victimization}

\section{Defining Peer Victimization}

Peer victimization is defined as the repeated negative actions directed toward a child by his or her peers with the intention of inflicting injury or pain (Crick \& Grotpeter, 1996; Olweus, 1993; Vernberg, Jacobs, \& Hershberger, 1999). While researchers indicate that isolated acts of victimization may cause significant harm to the child, it is evident that repeated victimization is more likely to increase the endurance and severity of subsequent adjustment problems (Kochenderfer-Ladd \& Wardrop, 2001). Further, the occurrence of victimization becomes more stable (e.g. $r=.70)$ over time, in particular, over the four year period throughout middle childhood and early adolescence (Paul \& Cillessen, 2003).

Provided these findings, a considerable amount of attention in the peer victimization research has focused on the detrimental effects associated with being a 
victim. These varied effects often include lowered self-esteem (Prinstein et al., 2001), depressive symptoms (Crick \& Bigbee, 1998; Prinstein et al., 2001), loneliness (Boivin \& Hymel, 1997), social withdrawal (Crick \& Bigbee, 1998), anxiety (Nishina et al., 2005), decreased academic engagement and lowered academic achievement (Buhs \& Ladd, 2001). Findings further suggest that those experiencing chronic victimization are at an even higher risk for these outcomes (Holt \& Espelage, 2003).

The research examining peer victimization will often also consider a closely related construct, peer rejection. Although peer rejection, the negative attitude of the social group toward the child (Boivin, Hymel, \& Bukowski, 1995), is a distinct construct from victimization (the actual behavioral expression of rejection), these two constructs tend to be highly correlated (e.g. $r=.92$, Buhs $\&$ Ladd, 2001). It is apparent that when a child is rejected and subsequently victimized by his or her peers, the social disengagement that persists is likely to increase the child's development of internalizing problems, in particular, their loneliness.

Taken together, it is evident that the level of rejection and subsequent victimization is linked to the presence and relative stability of victimization, a finding that has lead a significant portion of the peer victimization research to focus on understanding the processes that lead to these negative outcomes. There are current researchers, though, who suggest that the landscape of peer victimization is much more heterogenous than past research has indicated (Hanish \& Guerra, 2002; KochenderferLadd \& Ladd, 2001; Kochenderfer-Ladd \& Skinner, 2002; Goodman \& Southam-Gerow, 2010). In the face of victimization from peers, some studies suggest there are children who report little to no effects on their adjustment (Hoover, Oliver, \& Hazler, 1992). In 
order to further understand what may lead to this heterogeneity amongst victimized children, researchers need to examine the various factors influencing the victimizationadjustment model.

\section{Forms of Victimization}

Studies suggest that the form of victimization has an important role in determining the effect it has on adjustment, a view that may help account for some of the differences in victimized children's adjustment (Roecker Phelps, 2001). Though forms of victimization have been delineated and defined in several ways throughout the literature, relational and overt victimization consistently appear as two distinct, yet related forms of victimization. Relational victimization is defined as damage to one's peer relationships and involves manipulation through methods such as gossip, rumors, and social exclusion (Crick \& Grotpeter, 1996). Further, relational victimization is often directed at individuals within the context of friendship (Grotpeter \& Crick, 1996). On the other hand, overt victimization characterized as harm that occurs through direct, physical and verbal means such as hitting or kicking (Crick \& Grotpeter, 1995), is often directed toward an individual outside of the context of friendship.

Provided these differences, it is evident that relational and overt victimization may pose different threats often leading to differential adjustment outcomes. Relational victimization is more likely to result in socially related consequences such as social avoidance and lower social preference from peers (Putallaz et al., 2007). Overtly victimized children, however, have frequently been found to be less concerned with maintaining social relationships. For example, relational victimization has been found to increase one's level of worry about preserving their peer relationships. This increased 
worry can decrease the likelihood that the child will engage in behaviors that could further threaten their peer relationships (e.g. aggression). On the other hand, overt victimization may lead to stress related to self-protection which can be an instigator for retaliatory aggression (Crick \& Dodge, 1996; Leadbeater et al., 1999).

\section{Influences on Peer Victimization}

Each form of victimization is further influenced by the developmental period in which it occurs. In middle childhood, for example, relational victimization frequently becomes more covert. For example, young children often directly state they will no longer be your friend if some demand isn't met, yet as children get older they are more likely to use the peer group as a pathway to relational victimization (Crick et al., 2002). For children in middle childhood, relational victimization is perceived not only as a threat at the individual level, but also as a threat to their social connection with peers (Crick \& Grotpeter, 1996). Conversely, overt victimization often occurs directly between two children, the aggressor and the victim. Subsequently, victims of overt aggression have been found to be less concerned with maintaining their peer relationships.

Research studies examining both forms of victimization have suggested that relationally victimized children experience significant socio-emotional challenges, including internalizing problems, even after overt victimization is controlled for (Crick \& Grotpeter, 1996; Paquette \& Underwood, 1999; Prinstein et al., 2001). It appears that because relationally victimized children are influenced primarily at the social level, they may subsequently have more to gain from protective factors apparent in one's social interactions. 
Further exacerbating these differences found between forms of victimization is the influence of the child's gender. Evidence suggests that, in general, girls are often (but not always) more likely to experience relational victimization while boys are more likely to experience overt victimization (Crick \& Bigbee, 1998; Ostrov \& Keating, 2004). What appears to account, in part, for these differences are the socialization of values behind social relationships that are evident for girls and boys (Crick \& Grotpeter, 1995). Findings indicate that girls typically value close relationships more highly (Block, 1983) and therefore are more likely to experience victimization in a form meant to jeopardize these relationships. Boys, in general, are more likely to value dominance-oriented goals (Block, 1983); goals that are more likely to be threatened by an outward, physical form of victimization.

Studies that consider both form of victimization and gender, though, have shown varied outcomes. For example, when examining overt and relational victimization, both boys and girls rated high on relational victimization were more likely to avoid social situations and had higher reports of loneliness (Putallaz et al., 2007). These findings suggest that although girls may have a higher prevalence of relational victimization, boys who are relationally victimized indicate similar forms of maladjustment. Some studies have also show that in early- to mid-childhood there are little to no gender differences in relational victimization and that the differences seen amongst genders are often not present until adolescence (Bjoerkqvist, Lagerspetz, \& Kaukiainen, 1992; ZimmerGembeck, Geiger, \& Crick, 2005). However, other findings indicate that girls are more relationally aggressive as early as preschool (Crick \& Grotpeter, 1995; Prinstein \& Cillessen, 2003). These inconsistencies within the research reiterate the need to study not 
only specific forms of victimization and adjustment, but to further examine the influence of gender within these analyses.

\section{Loneliness}

Given the above findings, it is evident that across the various forms of victimization there is a consistent link with internalizing problems. Of these internalizing problems, studies that considering age, grade, culture, and measurement type, have indicated that loneliness is most consistently and positively related to the presence of peer victimization (Kochenderfer-Ladd \& Wardrop, 2001). Findings suggest that as victimization occurs, it often leads to higher levels of social exclusion and social avoidance and, in turn, increased levels of loneliness (Crick \& Bigbee, 1998; Storch, Masia-Varner, \& Brassard, 2003).

Further, researchers have defined the specific steps through which victimization and loneliness may often be linked (Crick \& Grotpeter, 1996). The model suggests that the process of victimization often brings an emotional reaction from the child. The child's emotional reaction (if negative) may lead to an increased likelihood of being perceived as a target for victimization and in turn increase the likelihood that the child is victimized. If this cycle persists, it may potentially exacerbate the child's emotional reaction even further. Given a negative emotional reaction and continued victimization, the cycle of stress on one's social and emotional development can in turn increase the likelihood that the child will suffer maladjustment. According to the social needs approach, loneliness, an emotional state developed as a result of social needs going unmet, is likely to persist (Asher \& Paquette, 2003; Jobe-Shields, Cohen, \& Parra, 2011). Provided this model, it is evident that considering how the child's social needs develop 
over time is also necessary. With the increase in concern for peer acceptance peaking throughout middle-childhood (Rubin, Bukowski, \& Parker, 2006), an increased role for loneliness also becomes more likely (Fontaine et al., 2009).

Considering this pattern of change in loneliness and victimization over time, it is likely that not all children will follow the same developmental trajectory. In a longitudinal study of third to fifth grade students, Jobe-Shields, Cohen, \& Parra (2011) found three distinct groups based on level of loneliness (stable-low, increasing, and decreasing) that emerged over time. In particular, their findings indicated that the mean level of children in the increasers' group (increasing levels of loneliness) also indicated increasing levels of victimization from third to fifth grade. Conversely, children in the decreasers' group (decreasing levels of loneliness) transitioned from high levels of victimization in third grade to increasingly lower levels of victimization in fourth and fifth grade. By fifth grade, the decreasers' were indistinguishable from the stable-low in overall peer optimism, liked-most nominations, mutual friendships, and levels of victimization. Although the study did not directly infer causes for the change in the construct levels, drawing on the social needs perspective (Asher \& Paquette, 2003), we may assume these changes leading to decreased loneliness may be due to more of the child's social needs being met. Thus, the child's behavior may serve to moderate the relationship between a child's social needs and subsequent loneliness.

For children who indicate decreasing levels of loneliness over time, one possible explanation for this decrease is their positive social behaviors. In accordance with a social needs theory, as a child's social needs begin to be met, their loneliness should begin to decrease. Thus, engaging in positive social behaviors may be one way to help 
alleviate insufficient social needs, and in turn serve as a protective factor for these children. Just as prior research indicated peer victimization was positively correlated with loneliness (Kochender \& Ladd, 1996); acting in positive, socially accepted ways is negatively correlated with loneliness (Eisenberg et al., 2006). By considering potential moderators of these relationships, such as a child's social behavior, researchers may begin to better understand the differences amongst victimized children's adjustment outcomes. Further, gaining a better understanding of behaviors that may serve as a protective factor for children by helping to reduce internalizing problems such as loneliness should be a primary goal for researchers.

\section{Prosocial Behaviors}

It is evident that victimization is part of a complex social process, one that appears to function, in part, through the subsequent behaviors a child engages in. Thus, in considering an expansion of the current profile of victimized children, it is increasingly evident that an important moderator between being victimized and subsequent adjustment is the child's social behavior. How a child acts throughout the process of being victimized will influence how the child is viewed by the aggressor and his or her peers and in turn influence how capable the child feels about handling the situation. The behavior thus becomes a way to cope with victimization and has an influence on subsequent adjustment (Kochenderfer-Ladd \& Skinner, 2002).

\section{Development of Prosocial Behavior}

When studying potential protective factors for children, it is important to examine the portion of research on social behavior and peer relationships that focuses on positive social behaviors evident among youth (Carlo, Crockett, Randall, \& Roesch, 2007; Scales, 
Benson, Leffert, \& Blyth, 2000). Positive social behavior or prosocial behaviors are aimed at benefiting another person or persons and often take the form of helping, sharing, and other acts of kindness (Carlo et al., 2007; Eisenberg, 2003). Beginning in middle childhood, researchers suggest that prosocial behaviors expand from the more traditional view of sharing and helping to also include the maintenance of social ties and other relationally inclusive behaviors present in peer relationships (Greener \& Crick, 1999). This expanded definition of prosocial behavior suggests there may be differences amongst children in both the expression and the likelihood of acting prosocially in adverse situations (e.g. victimization experiences).

The gender of the child may also play a role in the social development of prosocial behaviors. In general, girls are expected to be more empathetic and prosocial while males are believed to be more achievement driven and independent; findings that have been consistent in cross-cultural research as well (Carlo, Roesch, Knight, \& Koller, 2001). Peers, especially girls, are more likely to nominate girls as being prosocial and to nominate boys as being bullies (Warden et al, 2003). To some degree, these differences seen in boys and girls may be because, even at a young age, peers often provide feedback for boys and girls based on what they are supposed to be (i.e. as conforming to stereotypes) rather than what they are (Eisenberg et al., 2006).

Further, the influence of the developmental period of the child is influential. Middle childhood, in particular, is a significant period for the development of prosocial behavior (Carlo et al., 2007). It is a time period in which cognitive abilities necessary to take another's perspective, higher levels of moral reasoning skills, and a sense of personal identity are all developing (Berndt \& Ladd, 1989; Brown, 1989). Throughout 
these crucial personal developments, the conformity to peer values and expectations also increases and peer feedback and modeling become crucial in shaping one's social behavior. Peers are unique influences in this development because of their relatively equal power (characteristics parents and educators lack). With the increase in comparison with peers, the task of establishing and maintaining one's peer network becomes increasingly complex as children move into early adolescence (Brown, 1989). Thus a crucial component in the development of peer relationships is a child's social behaviors. These behavior patterns are likely to have a role in determining the level of peer acceptance or rejection a child or adolescent incurs (Carlo, Raffaelli, Laible, \& Meyer, 1999; Schonert-Reichl, 1999; Wentzel \& Asher, 1995).

Overall, the feedback from peers on early social behaviors may inevitably influence the development of a child's future behavior patterns, either in a positive or negative way. These socialization experiences from peers, a primary source for the development of prosocial behaviors, may be lacking for victimized children. In contrast, children who are victimized and continue to act prosocially, thus maintaining more frequent peer interactions, may be more likely to show resiliency toward maladjustment from victimization. Provided the protective role they may provide, it seems pertinent to study the unique role prosocial behaviors could have for victimized children.

\section{Prosocial Behavior as a Protective Factor}

Although researchers acknowledge the various influences on prosocial behavior development and victimization separately, when examining the relationship between these two constructs, the research has often focused on their relationship as bidirectional. These findings indicate that victimized children are more likely to engage in submissive, 
withdrawn, or aggressive social behaviors which perpetuate the cycle of victimization (Boivin, Hymel, \& Bukowski, 1995) while children engaged in positive, prosocial behaviors are at a lower risk for peer victimization (Egan \& Perry, 1998; Schwartz, Dodge, \& Coie, 1993). Yet current research findings suggest there is more heterogeneity in the profiles of victimized children than prior research has suggested, and that these differences may lead to varied adjustment outcomes for victimized children.

For example, in a study primarily utilizing peer-nominations, it was found that victimization did not increase depression, anxiety, or social withdrawal in first, second, and fourth grade children over a 2-year period (Hanish \& Guerra, 2002). Further, in a study examining fourth and sixth grade children, Khatri and colleagues (2000) found no relations between victimization and self-rated depression. Findings have also indicated that although almost all school-age children report being a victim of bullying at least once, many of these children report not feeling this experience severely affected them (Hoover, Oliver, \& Hazler, 1992).

Taken together, this evidence supports the heterogeneity amongst children's responses to victimization making it is increasingly apparent that simply examining the relationship between victimization and adjustment is inadequate. Although there is a strong relationship between peer victimization and maladjustment, these findings provide evidence that not all outcomes are negative. Victimized individuals who have the opportunity or inclination to engage in positive social behaviors (e.g. prosocial behaviors) may be less likely to marginalize themselves from peer activities and further decrease the likelihood of maladjustment. It is a goal of the current study to examine the unique profile of victimized children with higher prosocial behavioral tendencies. By examining 
the interaction between victimization, and protective factors, such as prosocial behaviors, we hope to gain a better picture of the complex process of peer victimization.

\section{Prosocial Behavior as a Coping Strategy}

An area of research which may provide a theoretical framework to shed light on this more complex process of victimization is the research on coping strategies. Most recently, coping strategies and emotional regulation processes have emerged as influential in the relationship between victimization and adjustment outcomes. Researchers suggest that the way in which children and adolescents cope with stress can be an important mediator or moderator of the impact stress has on both concurrent and future adjustment (Compas et al., 2001; Kochenderfer-Ladd, 2004). Although the current study does not examine coping strategies directly, prosocial behaviors are examined as an aspect of coping strategies for children. Thus, examination of the coping literature may assist to further our knowledge of prosocial behaviors as a protective factor within the victimization process.

Coping strategies are defined as the dynamic process of attempting to reduce or eliminate stressors through cognitive or behavioral responses (Lazarus \& Folkman, 1984; Compas et al., 2001). According to a transactional model of coping (Lazarus, 1991), an individual's primary appraisal of an event or situation as threatening, harmful, or challenging, along with their secondary appraisal of whether or not they have the resources to cope with the stressful event, influences the type of coping strategy that is deployed. The coping strategy utilized can either reduce or exacerbate the negative feelings that result from a stressful event and/or may assist to eliminate effects of the stressful event all together. The adjustment that follows a stressful situation is seen as a 
function of the coping strategies deployed. The secondary appraisal step (Lazarus, 1991) suggests that individuals, given a stressful situation, will then evaluate their ability to reduce the impact of the negative emotions elicited by the event. It is in this process that individuals perceive whether or not they have the adequate resources to handle a stressful situation. If these resources are believed to be low, any negative emotions apparent are exacerbated (Lengua \& Long, 2002). If the resources are believed to be high and the individual engages in an appropriate coping strategy, the level of stress is often minimized or eliminated.

\section{Type of Coping Strategy}

When conceptualizing the differences in children's coping strategies, a common categorization is to determine whether a child engages in an approach or avoidance response. Approach coping includes active problem-solving of the situation such as seeking social support or engaging in appropriate social behaviors. Avoidance coping includes distancing oneself by either worrying about the situation or getting mad and acting out within the situation. Often children utilize a combination of both approach and avoidance strategies, tailoring a specific coping strategy for each stressful situation.

The type of coping strategy deployed in response to social stressors can further

lead to varied outcomes. Approach/active coping strategies (directed attempts to deviate from stressful situations) rather than avoidant coping may have a greater capability of buffering the effects of peer victimization (Kochenderfer-Ladd \& Skinner, 2002). Victims engaged in approach strategies in which they were able to divert their attention from the stresses of peer rejection and instead focus on more pleasant activities were found to reduce the negative adjustment associated with peer victimization (i.e. 
loneliness). Individuals who used avoidant coping strategies were found to have higher rates of loneliness and increased maladjustment. Findings indicating approach strategies moderate the relationship between peer victimization and adjustment provide support to the notion that prosocial behaviors may serve as a moderator of this relationship. Further, as Kochenderfer-Ladd (2004) points out, it is possible that coping strategies will not stop the occurrence of victimization and yet they can still serve as a protective factor against internalizing problems. This is more likely to occur when the child feels in control of the situation and implements an appropriate coping strategy.

In a study utilizing self-report measures of loneliness, peer victimization, and coping strategies, fifth graders indicated that frequent victimization increased levels of loneliness. However, these findings were contingent upon two interactions: (1) victimized children who were more likely to cope by internalizing methods (e.g. worry) reported higher levels of loneliness than those not relying on internalizing coping (2) victimized children coping through seeking out social support indicated significantly less loneliness than children engaged in other styles of coping (Skinner \& KochenderferLadd, 2000). Further, how the child reacted emotionally was influential on the child's subsequent coping abilities. Victimized children often perceive themselves as having limited resources for handling stress, yet if they are able to act prosocially as a way to cope with victimization, it may increase their perception of adequate resources and, in turn, decrease their stress.

\section{Gender Differences in Coping}

To date, the literature focused on gender differences in coping strategies for peer victimization is inconclusive. In a study of children ages five to seven, researchers found 
that girls were more likely than boys to engage in behavior that mitigates conflict laden situations (Miller, Danaher, \& Forbes, 1986). Girls were more likely to use strategies to further discussion of emotions within the situation or to compromise at another's request. Boys, on the other hand, were more likely to use physical force or threats in the face of conflict. It appears that girls were more likely to walk away from the conflict and seek support if necessary whereas boys were shown to more often fight back and actively engage in the situation at that time (Fabes \& Eisenberg, 1992; Kochenderfer \& Ladd, 1997; Smith, Shu, \& Madsen, 2001).

Visconti and Troop-Gordon (2010) found among a sample of fourth and fifth graders that girls who reported higher levels of avoidance coping had decreased prosocial behaviors, while for boys higher avoidance coping actually indicated increased prosocial behaviors. Further, prior research proposes that girls seek to resolve conflicts in a more amicable way, revealing an increased desire to maintain social relationships in the midst of conflict. Thus, the act of avoiding as a method of coping with victimization for girls may lead to negative social consequences. Conversely, boys able to use avoidance as a coping strategy may allow them time to decrease tension and thus can be construed as a positive social behavior (Visconti \& Troop-Gordon, 2010). These findings suggest that the effects of engaging in certain coping strategies may be different for girls and boys.

Researchers also suggest that the emotional response differences between girls and boys may be influential in this process. Girls in general appear to be more expressive emotionally than boys (Ruble \& Martin, 1998). It is probable, however, that appropriate coping and emotional responses that include some engagement in prosocial behaviors may be beneficial for any child. Provided the above research, it is evident that effective 
coping is often predicated on an individual's ability to manage their emotional reaction to a stressful situation. Unfortunately, to date, emotional regulation is an area that has not been extensively examined within the victimization literature (Goodman \& SothamGerow, 2010).

\section{The Role of Emotional Regulation}

This notion of effective emotional regulation, specifically in examining the role of prosocial behavior as a coping mechanism, is a model researchers have indicated is appropriate (Eisenberg et al., 1996). Emotional regulation is the affective, cognitive, and behavioral process through which an individual influences both their experience and expression of emotions (Gross, 1998). Unfortunately, as Goodman and Sotham-Gerow (2010) point out, a key limitation in the peer victimization literature has been the failure to examine the role of emotions in coping with victimization. Current victimization research can benefit from examining emotional regulation because the variations in emotional regulation and response may, in part, explain the differences in children's adjustment to peer victimization. Knowledge of emotional regulation is thus potentially important when examining the heterogeneity in the coping strategies of victimized children and in suggesting why some children cope through prosocial behaviors and others do not.

To date, the majority of victimization literature that has examined emotional regulation has focused on negative emotional responses. Negative emotional response or lack of emotional regulation can lead to ineffective coping and increased maladjustment such as depression and other conduct issues (Sandler et al., 2000). Lack of emotional regulation is also associated with higher levels of negative social behaviors toward peers 
(e.g. aggression; Eisenberg et al., 1993). Although significantly fewer studies have examined positive emotional responses and coping in stressful situations, those that have been reported reveal lowered levels of internalizing problems (Jackson \& Warren, 2000; Lengua \& Long, 2002; Santiago-Rivera, Bernstein, \& Grad, 1995). It appears that the ability to self regulate lessened the effects of stress on children's adjustment (Lengua \& Long, 2002). Further, the ability to control negative emotions and effectively cope with stressful, emotional situations (e.g. victimization) is integral in the development of prosocial behaviors (Eisenberg \& Fabes, 1992).

Self-regulation was also predictive of active (approach) coping, assisting in the mitigation of the impact of negative life events on a child's adjustment. Further, previous findings have indicated a positive appraisal of a stressful situation (the belief that one has the capacity to deal with the situation) is often predictive of active coping (Jackson \& Warren, 2000; Santiago-Rivera et al., 1995). In the case of peer victimization, acting prosocially may be a way children can actively cope with their situation. Thus, it is evident that emotional regulation appears to be a process that may either exacerbate or buffer the effect victimization has on a child's adjustment.

Self-report data collected from fifth graders revealed that when victimized children were given a hypothetical dilemma on peer aggression they were more likely to experience intense negative emotions than those who were non-victims (KochenderferLadd, 2004). Yet, it was their ability to regulate their emotional response that indicated whether their coping strategy was adaptive or maladaptive for later adjustment. The children who reported emotions such as fear were more likely to cope in an adaptive way (i.e. actively seeking advice) which was predictive of less internalizing problems. 
Conversely, children who reported anger were less likely to cope adaptively and in turn had higher rates of internalizing problems. The differential effects seen amongst these victimized children's adjustment appears to function due to their emotional reactions and the subsequent influence it has on their coping strategies.

It appears that of children who are victimized, those able to regulate their emotional reactions to their victimization experiences have an increased likelihood of coping with the situation by actively engaging in prosocial behaviors. Prior research suggests children who cope prosocially as opposed to those who cope antisocially are less likely to display maladjustment such as depression or loneliness (Glyshaw, Cohen, \& Towbes, 1989). Fabes and colleagues (1994) also found that children who were able to optimally regulate their emotional response in a high stress situation were more likely to show sympathy than to focus on their personal distress when confronted with another's distress. Children who cope appropriately and display sympathy in high stress situations are also more likely to react in socially constructive ways (e.g. prosocial responses). Emotions thus appear to play an important role in both coping strategies and the potential use of prosocial behaviors in response to social stressors (Eisenberg et al., 2006). As discussed previously, engagement in prosocial behaviors often increases in late childhood and early adolescence and is associated with the maturation of cognitive capability to take another's perspective. Hoffman (1982) suggests that an increase in a child's perspective taking ability gives rise to the ability to differentiate between one's own and another's distress, a capability necessary for proper emotional regulation. Perspective taking allows one to develop a sense of sympathy for others and its development is often correlated with one's emotional regulation and prosocial behavior 
(e.g., Carlo et al., 2003; Eisenberg, Zhou, \& Koller, 2001). Hoglund (2005) also found that individual differences are apparent in the level of social-cognitive capabilities (perspective taking and interpersonal skills) amongst victimized children. Understanding these individual differences not only in a child's inability to engage in such processes, but also in a child's ability to engage in these processes in the face of victimization, would be beneficial for understanding the social and cognitive process linked to peer victimization.

By around mid- to late-childhood, there also appears to be an increase in empathy as older children are less likely than younger to weigh the costs to the self when deciding to engage in prosocial behavior (Eisenberg, 1986). Older children who are victimized and yet are able to engage in perspective taking may be more likely to look past their personal distress and plight in order to engage in prosocial behaviors. Effective emotional regulation, perspective taking, sympathy, and moral reasoning skills have been found to support relatively high levels of prosocial behaviors and low levels of disruptive and aggressive behaviors (Eisenberg et al., 2006). Engagement in prosocial behaviors can further lead to several positive outcomes including an increase in self-esteem, selfacceptance, moral development, and belief in one's personal responsibility to help (Conrad \& Hedin, 1982, Eisenberg et al., 2006) and lead to decreases in negative outcomes often associated with victimization.

\section{The Current Model}

To date, studies in peer victimization have apparently not yet examined prosocial behavior as a protective factor for victimized children. Thus, the empirical model for the current study will examine children's prosocial behavioral tendencies as a possible moderator in the relationship between peer victimization and loneliness. This moderation 
model will be examined among a sample of European-American and Latino children in middle childhood (grades 4 and 5). A common assessment for both peer victimization and prosocial behaviors amongst elementary age children is peer nominations, the measurement currently utilized.

In the present study, peer victimization is defined as the repeated negative actions directed toward a child by his or her peers with the intention of inflicting injury or pain (Crick \& Grotpeter, 1996; Olweus, 1993; Vernberg, Jacobs, \& Hershberger, 1999). As previously described, victimization is also delineated in this study into two forms, relational and overt. Relational victimization is defined specifically as the behaviors intended to harm peers through manipulation and damage to a child's peer relationships (Crick, 1995). These behaviors are measured through items that tap behaviors such as talking behind one's back or gossiping. In the current study, items tapping social exclusion (e.g. being left out of everyday activities) are also included in the measure of relational victimization as prior research has suggested that social exclusion is an important aspect of relational victimization (Underwood et al., 2004). Overt victimization is measured by items tapping behaviors such as physical (e.g. hitting) and verbal (e.g. insults) behaviors which are intended to harm others.

In testing a model that has not previously been explored, it is important to examine victimization in its various forms. Prior research indicates relational and overt victimization tend to be moderately to highly correlated suggesting that examining a total victimization score may be useful. Thus, the current study will examine victimization as a total score within the initial models. There are also findings that suggest overt and relational victimization are distinctly defined constructs that can be examined separately 
in terms of adjustment (e.g. Crick \& Grotpeter, 1996; Vaillancourt, Brendgen, Boivin, \& Tremblay, 2003). The current study will also examine relational and overt victimization as separate models.

Prosocial behavior is defined in the current study as children's behaviors which are viewed as friendly toward or helping others. Although researchers have examined specific types of prosocial behaviors including behaviors such as public and anonymous prosocial tendencies in adolescents and young adults using self-report measures (Carlo et al, 2007), studies amongst elementary age children continue to examine prosocial behavior through peer nominations and as a global measure. Prosocial behaviors were assessed in the current study by asking students to nominate peers who were friendly toward others and who helped others.

\section{Prosocial Peer Support}

Working from the theoretical framework of coping strategies, prosocial behavior research within similar models have primarily focused on the receipt of prosocial behaviors as a protective factor for victimized children. For example, in a study of sixth and eighth grade students, researchers found that higher frequency of prosocial experiences, defined as emotional and tangible support received from prosocial interactions, were associated with higher overall life satisfaction across all levels of victimization (Martin \& Huebner, 2007). This suggests that the receipt of prosocial experiences can serve as a general protective factor, decreasing the negative impact victimization experiences may have on a child's overall emotional well-being. As prosocial experiences increase in child and adolescent interactions, the stress that arises from peer victimization tends to diminish (Martin \& Huebner, 2007). 
Further, in studies looking at the moderating role of prosocial support between peer victimization and loneliness, the effect of the peer maltreatment on loneliness was found to be partially moderated by prosocial support from peers. Positive prosocial experiences were found to facilitate the development of self-esteem, social skills, and interpersonal competences which serve to neutralize the experience of being victimized (Schwartz, Dodge, Pettit, \& Bates, 2000). Together, the research findings indicate strong support for the contention that prosocial support from peers can serve as a "buffer" or protective factor from the negative outcomes of victimization (Storch \& Brassard, 2003). A goal of the current study is to examine whether a similar level of protection is available from acting prosocially. Although not directly examined within these previous models, having a prosocial behavioral tendency has been found to provide rejected peers with an opportunity to build self-esteem and practice social skills in a safe environment (Hodges et al., 1999), and thus may adequately protect victimized children from maladjustment. In order to establish the unique role of prosocial behaviors within our model, the current study will control for the child's perceived level of prosocial support. Perceived prosocial support is assessed using a self-report measure asking children how often they feel support from their peers (e.g. being helped or complimented by one's peers). A selfreport measure is utilized because of the variability often found in children's perceptions of what is a necessary level of support. Although some children perceive adequate prosocial support from a few interactions with a small number of peers, others may consider more or less support to be adequate. 


\section{Necessary Level of Prosociality}

In examining the moderation of prosocial behavior in the relationship between victimization and loneliness, it is evident that examining the level of prosocial behavior and victimization together will allow an estimate of the influence on a child's loneliness. In a study examining prosocial support from peers, Vitaro and colleagues (1990) compared the social behaviors of children in kindergarten and first grade in terms of the stability of their rejected status. Peer nomination measures along with teacher reported behavioral assessments were administered to the children in kindergarten and then again in first grade. The researchers found about one-third of the children who were nominated as rejected in kindergarten maintained their rejected status (often strongly predictive of victimization) in first grade. In examining social behaviors, results showed that at Time 1, stable rejected children had a lower prosociality score than the unstable rejected children. When examining Time 2 scores, boys with unstable rejected statuses showed an increase in prosociality. This was also found amongst the girls at time 2 , but in the peer data only.

These findings suggest that prosocial behavior similar to or above the levels of others around you (at the mean or above) places rejected children at a lower risk for maintaining their rejected status. Rejected children with prosocial experiences, yet falling even one-half standard deviation below the mean, did not benefit from this protective factor and continued their rejected status (Vitaro, Gagnon, \& Tremblay, 1990). Thus, prosocial behavior appears to serve as a protective factor for children, but only if children are engaged more than average when compared to their peers. 
It is important in the current model to examine the level of prosocial behavior along with the level of victimization. If engagement in prosocial behavior serves as a protective factor for victimized children, it is important to know whether children have to engage in prosocial behaviors at a certain level in order for it to buffer the effects of maladjustment. Further, understanding at what levels of victimization prosocial behaviors serve to alleviate the stress associated with victimization is also needed.

\section{Purpose of the Study}

To date, studies in peer victimization have often overlooked the role of prosocial behavior for victimized children. Prosocial behaviors could potentially protect victimized children from subsequent internalizing problems, in particular their level of loneliness. Thus, a study examining prosocial behavior within the victimizationadjustment model is necessary.

The primary purpose of this study is to test a moderation hypothesis among victimization, prosocial behaviors, and loneliness. This hypothesis is based upon the theoretical framework of coping strategies which suggests that the individuals able to engage in appropriate, approach coping in the face of stress are less likely to suffer from negative outcomes related to such stressors. It is hypothesized that prosocial behaviors will moderate the relationship between peer victimization and loneliness. Specifically, children who are highly victimized and acting prosocially will show significantly less loneliness than children who are highly victimized and are not acting prosocially.

Further, understanding these associations amongst the different forms of victimization is important. Discriminate validity of relational and overt victimization has been established by prior researchers (Crick \& Grotpeter, 1996) suggesting that unique, 
valuable differences can be found for each form of victimization. The current study will examine each form of victimization separately as well as with a composite score combining scores from both forms. For children able to cope with relational victimization through prosocial behaviors, the positive behavior may assist to offset worry regarding their peer relationships and provide more positive peer interactions. These positive peer interactions coupled with lower levels of worry are likely to decrease their chances of suffering from social exclusion and subsequently, being lonely. It is hypothesized that prosocial behaviors will moderate the relationship between victimization and loneliness primarily for those individuals who have been relationally victimized.

Finally, each model will be examined by gender group. Prior research regarding the form of victimization and gender indicate that girls may be more likely to suffer from relational victimization, while boys are more likely to suffer from overt. Other studies suggest differences between genders in minimal when examining form and subsequent adjustment. Thus, the current study will provide initial insight into the role of prosocial behaviors for both boys and girls who are victimized. 
Chapter III: Methods

\section{Participants}

Data for the present study were drawn from Year One and Two of a larger, fouryear longitudinal study investigating peer relationships. The total sample consisted of 511 elementary school children with a minimum pairing on any two variables totaling 380 participants. Data were collected in the Spring of $4^{\text {th }}$ grade $(M$ age $=10.62, S D=.76)$ and the Spring of $5^{\text {th }}$ grade $(M$ age $=11.3, \mathrm{SD}=.71)$. Participants included 249 males and 262 females with an ethnic composition of 1.3\% Asian American, 1.1\% African American, 43.4\% European American, 48.2\% Hispanic, 1.9\% Native American, and 4\% other. Overall, a total of 27 classrooms were surveyed with the number of students in each classroom ranging from 10-25.

\section{Procedures}

Parental and youth consent were obtained from all participants. Participants were assessed in public schools from two small Midwestern cities located in rural areas. Data were collected by the primary investigator and trained graduate students in the Spring of fourth grade (T1) and one year later in the Spring of fifth grade (T2). Instruments used in the study were paper-pencil measures in the English language. Participants completed a demographic questionnaire assessing age, gender, and ethnicity.

\section{Measures}

Victimization: Peer-report. Peer nominations of victimization were measured using rosters of classmates. Students nominated peers who "other kids often leave out of conversations, games or activities" or who "other kids gossiped about or said bad things about behind their backs" (relational victimization) and who "were hit, pushed, and 
kicked" or who "get called bad names (teased, insulted) by other kids" (overt victimization). Students were directed to limit nominations to three peers for each item. Peer nominations for each student were standardized within each classroom and summed to calculate each respective victimization scale (Relational: $M=2.81, S D=2.74$; Overt: $M=2.57, S D=2.47$; Total: $M=2.69, S D=2.48)$. Cronbach's alpha were .94 for the 5 item relational scale, .85 for the 3 item overt scale, and .94 for the 8 item total victimization scale.

Prosocial Behavior: Peer-report. Prosocial behavior was also assessed using peer rosters of classmates. Similar to the victimization items, students were directed to limit nominations to three peers for each item. The two item prosocial scale asked students to nominate peers who "are friendly towards lots of other kids" and who "help other kids the most". Peer nominations for each student were standardized within each classroom $(M=5.17, S D=3.15)$ and summed to create a total prosocial score (Cronbach's $\alpha=.83$ ). Given that peer nominations are based on information drawn from multiple raters, single-item scales may produce high interrater reliability (see Coie, Terry, Lenox, Lochman, \& Hyman, 1995).

Prosocial Peer Support: Self-report. Student's perceptions of the supportiveness of their classroom peer group was assessed using the Perceptions of Peer Social Support Scale (PPSSS; Ladd, Kochenderfer, \& Coleman, 1996). Student's responded to items on a 5-point likert scale ( $1=$ Almost Never, $2=\mathrm{A}$ Little, $3=$ Sometimes, 4=A Lot, 5=Almost Always) assessing how often they received support from peers $(M=$ $3.19, S D=.99$ ). Example items from the six item scale include "How often do the kids 
in your class tell you you're good at things?" and "How often do the kids in your class help you if someone is teasing you?" $(\alpha=.87)$.

Loneliness: Self-report. Feelings of loneliness were measured using five items from the Loneliness and Social Dissatisfaction Questionnaire (Cassidy \& Asher, 1992). Students reported on a 5-point likert scale (1=Almost Never, 2=A Little, 3=Sometimes, 4=A Lot, 5=Almost Always) regarding how often they felt sad or alone at school.

Example items include "Is school a lonely place for you?" or "Are you alone or sad at school?". Scores for each item were summed and a mean value was taken to create an overall loneliness score $(M=1.97, S D=1.00)$. Internal reliability for these items were adequate for both the Spring of fourth-grade $(\alpha=.86)$ and the Spring of fifth-grade $(\alpha=$ .86) data. 


\section{Chapter IV: Results}

\section{Descriptive Statistics}

Number of participants, minimum and maximum scores, means, and standard deviations for the model variables are shown in Table 1. Bivariate correlations among the model variables are presented for the total sample (see Table 2) as well as separately by gender (see Table 3 ).

\section{Plan for Data Analysis}

Before testing for interaction effects, all predictors were centered to control for possible multicollinearity among the predictor variables (Aiken \& West, 1991). As outlined by Baron and Kenny (1986), the moderator hypothesis is supported if the interaction path calculated by multiplying the predictor (victimization) and proposed moderator variable (prosocial behavior) is significant. Though there may be significant main effects for the predictor and moderator, independently they are not directly relevant to testing the moderator hypothesis. Thus, the primary focus in reporting the results of a moderation model is on the significance or non-significance of the interaction term.

A series of just-identified models were estimated using SEM analyses to test the interaction of the child's overall victimization and prosocial behavior on loneliness (T2) as well as the interaction by type of victimization (relational or overt) and prosocial behavior on loneliness (T2). The control variables, loneliness (T1) and perceived social support (T1), were also included in all models. The series of models where then further examined separately by gender. Analyses of the hypothesized models were tested using MPlus, v. 5.1 software (Muthen \& Muthen, 2006). 
Table 1

Descriptive Statistics for Model Variables

\begin{tabular}{lccccc}
\hline Variable & $\mathrm{N}$ & Minimum & Maximum & Mean & SD \\
\hline Self-report & & & & & \\
$\quad$ Time 1 Loneliness & 374 & 1.00 & 5.00 & 1.96 & 1.00 \\
$\quad$ Time 2 Loneliness & 289 & 1.00 & 5.00 & 1.77 & .93 \\
$\quad$ Prosocial Peer Support & 371 & 1.00 & 5.00 & 3.19 & .99 \\
Peer-nomination (Z-scores) & & & & & .00 \\
$\quad$ Total Victimization & 380 & -.96 & 4.21 & .83 \\
$\quad$ Relational Victimization & 380 & -1.11 & 4.28 & .00 & .88 \\
$\quad$ Overt Victimization & 380 & -1.33 & 4.41 & .00 & .86 \\
$\quad$ Prosocial Behavior & 380 & -2.07 & 3.28 & .00 & .91 \\
\hline
\end{tabular}

Table 2

Bivariate correlations for structural model variables

\begin{tabular}{|c|c|c|c|c|c|c|c|}
\hline & 1 & 2 & 3 & 4 & 5 & 6 & 7 \\
\hline \multicolumn{8}{|l|}{ 1. Time 1 Loneliness } \\
\hline 2. Time 2 Loneliness & $.24 * *$ & & & & & & \\
\hline 3. Total Victimization & $.37 * *$ & .07 & & & & & \\
\hline 4. Relational Victimization & $.38 * *$ & .09 & $.95^{* *}$ & & & & \\
\hline 5. Overt Victimization & $.31 * *$ & .04 & $.95 * *$ & $.80 * *$ & & & \\
\hline 6. Perceived Peer Support & $-.43 * *$ & -.15 & $-.28 * *$ & $-.30 * *$ & $-.23 *$ & & \\
\hline 7. Prosocial Behavior & $-.27 * *$ & -.13 & $-.46 * *$ & $-.50 * *$ & $-.37 * *$ & $.27 * *$ & \\
\hline
\end{tabular}
Note. ${ }^{*} p<.05, * * p<.01$. 
Table 3

Bivariate correlations for structural model variables by gender groups

\begin{tabular}{|c|c|c|c|c|c|c|c|}
\hline & 1 & 2 & 3 & 4 & 5 & 6 & 7 \\
\hline 1. Time 1 Loneliness & & .15 & $.40 * *$ & $.42 * *$ & $.34 * *$ & $-.42 * *$ & $-.28 * *$ \\
\hline 2. Time 2 Loneliness & $.36^{* *}$ & & .10 & .13 & .05 & -.02 & -.03 \\
\hline 3. Total Victimization & $.33 * *$ & .06 & & $.95 * *$ & $.95 * *$ & $-.25 * *$ & $-.45 * *$ \\
\hline 4. Relational Victimization & $.33 * *$ & .08 & $.95 * *$ & & $.82 * *$ & $-.26 * *$ & $-.50 * *$ \\
\hline 5. Overt Victimization & $.29 * *$ & .03 & $.94 * *$ & $.77 * *$ & & $-.21 * *$ & $-.35 * *$ \\
\hline 6. Perceived Peer Support & $-.44 * *$ & $-.31 * *$ & $-.33 * *$ & $-.36 * *$ & $-.25 * *$ & & $.26^{* *}$ \\
\hline 7. Prosocial Behavior & $-.31 * *$ & -.16 & $-.45 * *$ & $-.49 * *$ & $-34 * *$ & $.32 * *$ & \\
\hline
\end{tabular}

Note. Males (top of the diagonal), Females (bottom of the diagonal)

$* p<.05, * * p<.01$.

\section{Structural Equation Model Testing for Moderation}

Initial analyses examined whether prosocial behavior (T1) moderated the link between type of victimization (T1) and loneliness (T2) while controlling for loneliness (T1) and perceived social support (T1) (see Figure 1). Prosocial support is controlled for in the proposed model to allow the current study to examine the possible protective effect of prosocial behavior for victimized children on later loneliness over and above the influence of a child's prosocial support.

The first model tested the interaction of total victimization, including both the relational and overt victimization scales, and prosocial behavior on loneliness (T2) (see Figure 2). In the total victimization x prosocial behavior model results indicated a justidentified model, $\chi^{2}=0(N=0), \mathrm{CFI}=1.0, \mathrm{SRMR}=.001, \mathrm{RMSE}=.00(\mathrm{CI}: .00, .00)$. The path estimate from the interaction term to loneliness (T2) was statistically significant 
$(\beta=-.24, p=.04)$ indicating prosocial behavior moderates the relationship between total victimization and loneliness one year later. Further, the path estimate for loneliness at time one ( $\beta=.22, p=.01)$ significantly predicted loneliness at time two. Path estimates for perceived social support, prosocial behavior, and relational victimization independently did not significantly predict loneliness at time two.

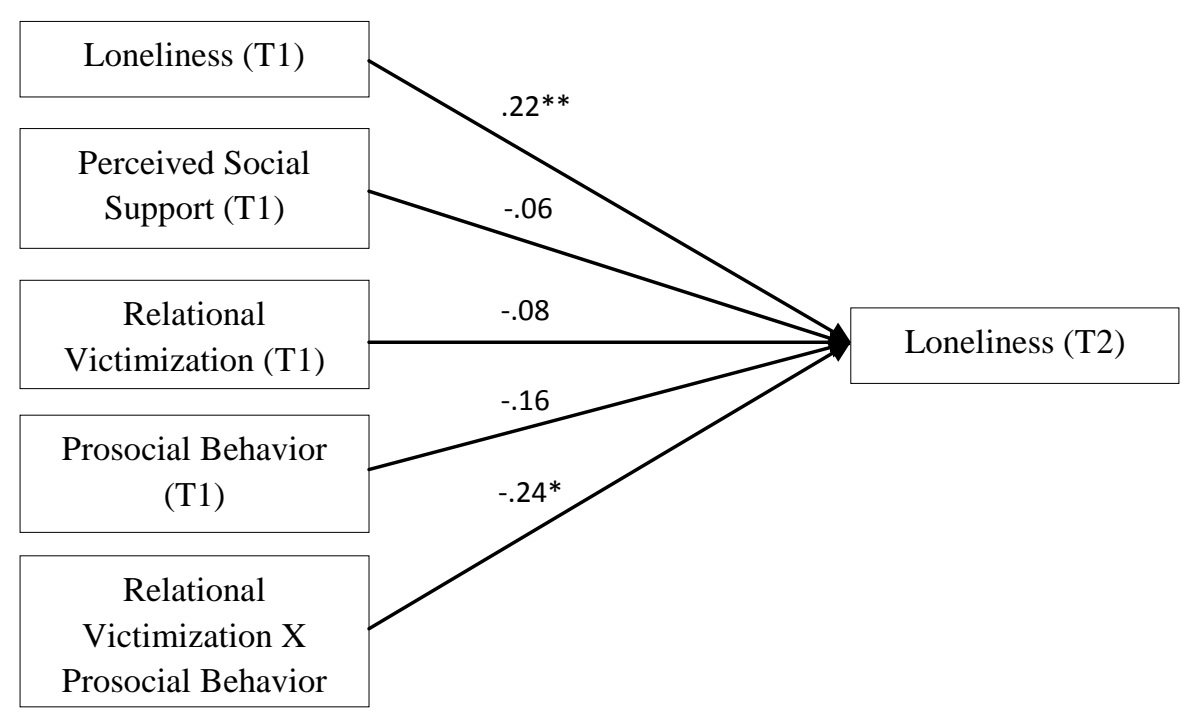

Figure 2. Total Victimization X Prosocial Behavior moderation model for the overall sample. Standardized regression coefficients are reported.

Next, separate models tested for the interaction of relational victimization $\mathrm{x}$ prosocial behavior and overt victimization x prosocial behavior on loneliness (T2). In the relational victimization x prosocial behavior model (Figure 3), results indicated a justidentified model, $\chi^{2}=0(N=0), \mathrm{CFI}=1.0, \mathrm{SRMR}=.00, \mathrm{RMSE}=.00(\mathrm{CI}: .00, .00)$. The path estimate from the interaction to loneliness (T2) was -.23, which was statistically significant $(p<.01)$. Path estimates for loneliness at time one $(\beta=.17, p=.03)$ and prosocial behavior $(\beta=-.19, p=.04)$ also significantly predicted loneliness at time two. 
Path estimates for perceived social support and relational victimization were nonsignificant. In the overt victimization x prosocial behavior model (Figure 4), results indicated a just-identified model, $\chi^{2}=0(N=0), \mathrm{CFI}=1.0, \mathrm{SRMR}=.00, \mathrm{RMSE}=.00$ (CI: .00, .00), but the path estimate from the interaction to loneliness (T2) was nonsignificant $(\beta=-.06, p=.62)$. Independently, the path estimate for loneliness at time one was significant $(\beta=.23, p=.01)$ while all other path estimates in the overt victimization $\mathrm{x}$ prosocial behavior model were non-significant.

Together these findings suggest that the significant interaction in the total victimization model is accounted for primarily by the interaction of relational victimization $\mathrm{x}$ prosocial behavior. That is, prosocial behaviors appear to moderate the relationship between victimization and loneliness over time for children who are relationally victimized but not for those who are overtly victimized.

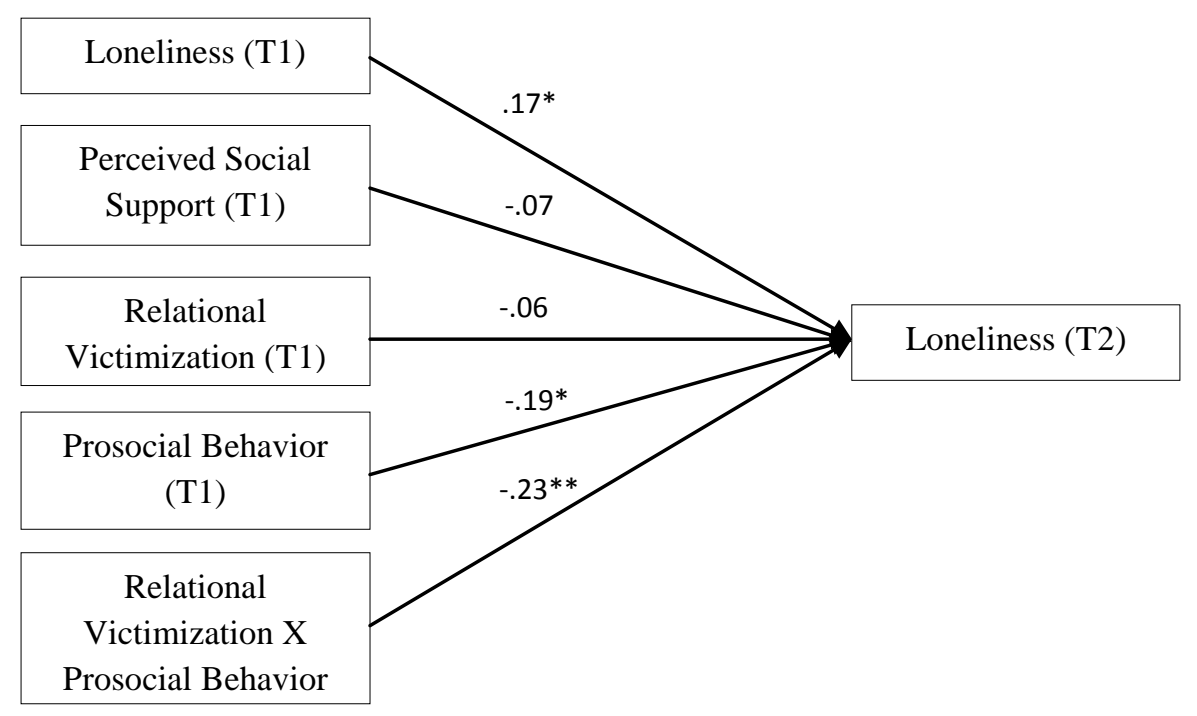

Figure 3. Relational Victimization X Prosocial Behavior moderation model for the overall sample. Standardized regression coefficients are reported. 


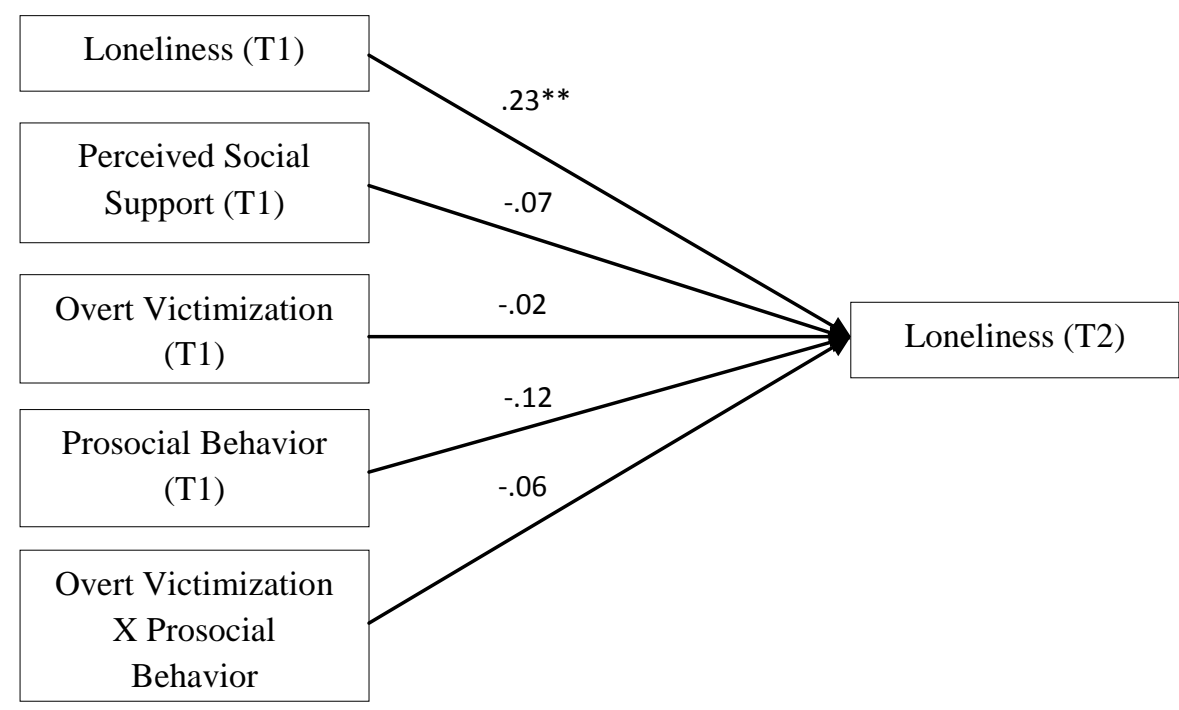

Figure 4. Overt Victimization X Prosocial Behavior moderation model for the overall sample. Standardized regression coefficients are reported.

\section{Structural Equation Model Testing for Moderation by Gender Groups}

Provided the research suggesting gender differences by type of victimization (Roeker-Phelps, 2001), a second set of analyses examined the initial models separately for boys and girls. For boys, the model examining the interaction of total victimization and prosocial behavior on loneliness (T2) indicated a just-identified model, $\chi^{2}=0(N=$ $0), \mathrm{CFI}=1.0, \mathrm{SRMR}=.00, \mathrm{RMSE}=.00(\mathrm{CI}: .00, .00)$ with a significant interaction term $(\beta=-.45, p=.04)$. All other path estimates within the total victimization model for boys were non-significant. Thus, amongst the boys in the sample prosocial behaviors moderated the relationship between total victimization and loneliness overtime. This was not found amongst the girls in the sample. For the girls, the interaction between prosocial behaviors and total victimization was not significant $(\beta=-.17, p=.16)$. Independently within the total victimization model for the girls, path estimates for loneliness at time one 
$(\beta=.31, p<.01)$ and prosocial behavior $(\beta=-.24, p=.02)$ were predictive of loneliness at time two.

Next, the type of victimization was further examined by gender. For boys, results for the relational victimization $\mathrm{x}$ prosocial behavior model indicated a just-identified model, $\chi^{2}=0(N=0), \mathrm{CFI}=1.0, \mathrm{SRMR}=.00, \mathrm{RMSE}=.00(\mathrm{CI}: .00, .00)$ with a significant interaction $(\beta=-.56, p=.003)$ (see Figure 4$)$. No other path estimates were independently significant within the model. For the overt victimization x prosocial behavior model (see Figure 6), all path estimates including the interaction term $(\beta=-.14$, $p=.58)$ were non-significant.

Similar results were seen amongst girls. The interaction in the relational victimization $\mathrm{x}$ prosocial behavior model (see Figure 5) was significant $(\beta=-.23, p=.04)$ and results indicated a just-identified model, $\chi^{2}=0(N=0), \mathrm{CFI}=1.0, \mathrm{SRMR}=.00$, $\mathrm{RMSE}=.00(\mathrm{CI}: .00, .00)$. Path estimates for loneliness at time one $(\beta=.31, p<.01)$ and prosocial behaviors $(\beta=-.24, p=.02)$ were also significant. Further, for girls the interaction in the overt victimization x prosocial behavior model (see Figure 7) was nonsignificant $(\beta=-.06, p=.62)$. Loneliness at time one $(\beta=.31, p<.01)$ and prosocial behaviors $(\beta=-.25, p=.02)$ were independently predictive of loneliness at time two within this model. Taken together, these findings suggest that for boys and girls, engagement in prosocial behaviors moderates the relationship between victimization and loneliness overtime when the victimization is relational, but not when it is overt. 


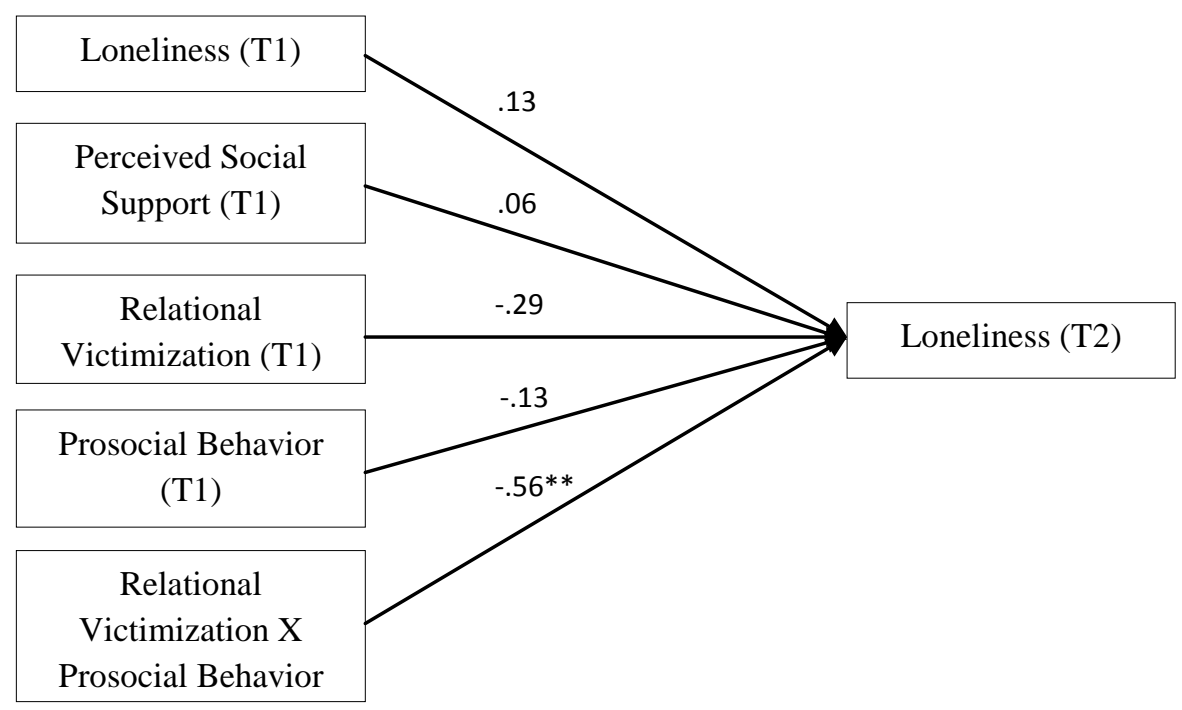

Figure 4. Relational Victimization X Prosocial Behavior moderation model for boys. Standardized regression coefficients are reported.

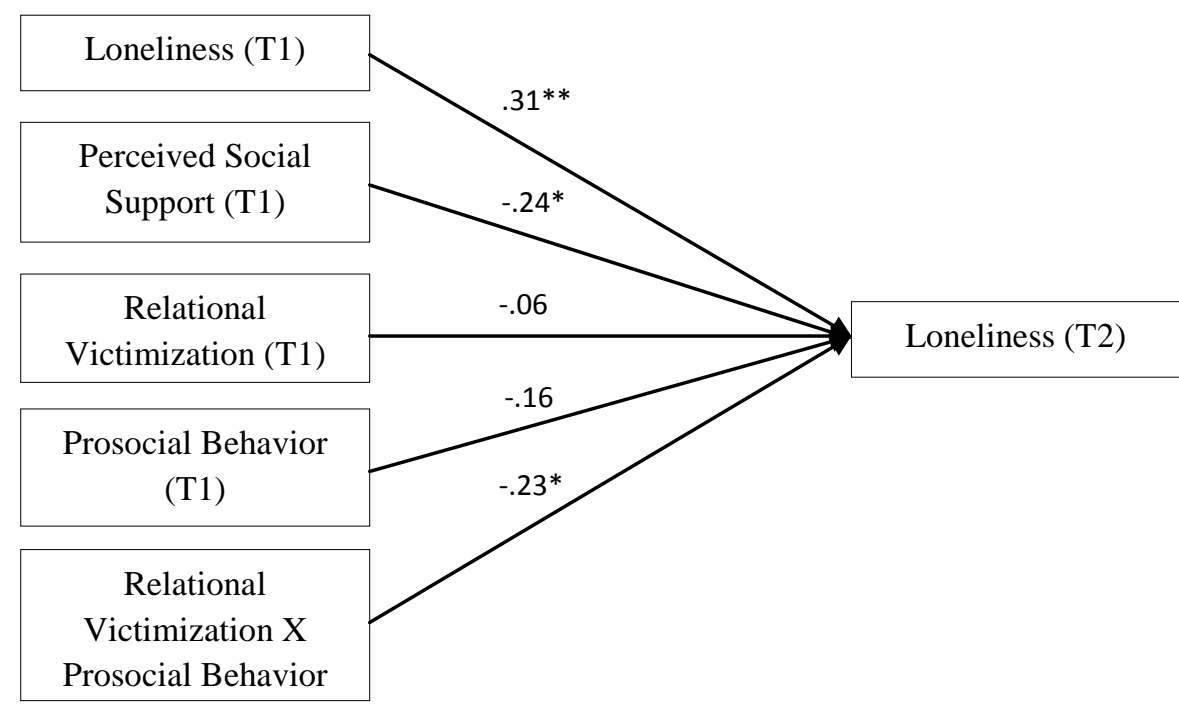

Figure 5. Relational Victimization X Prosocial Behavior moderation model for girls. Standardized regression coefficients are reported. 


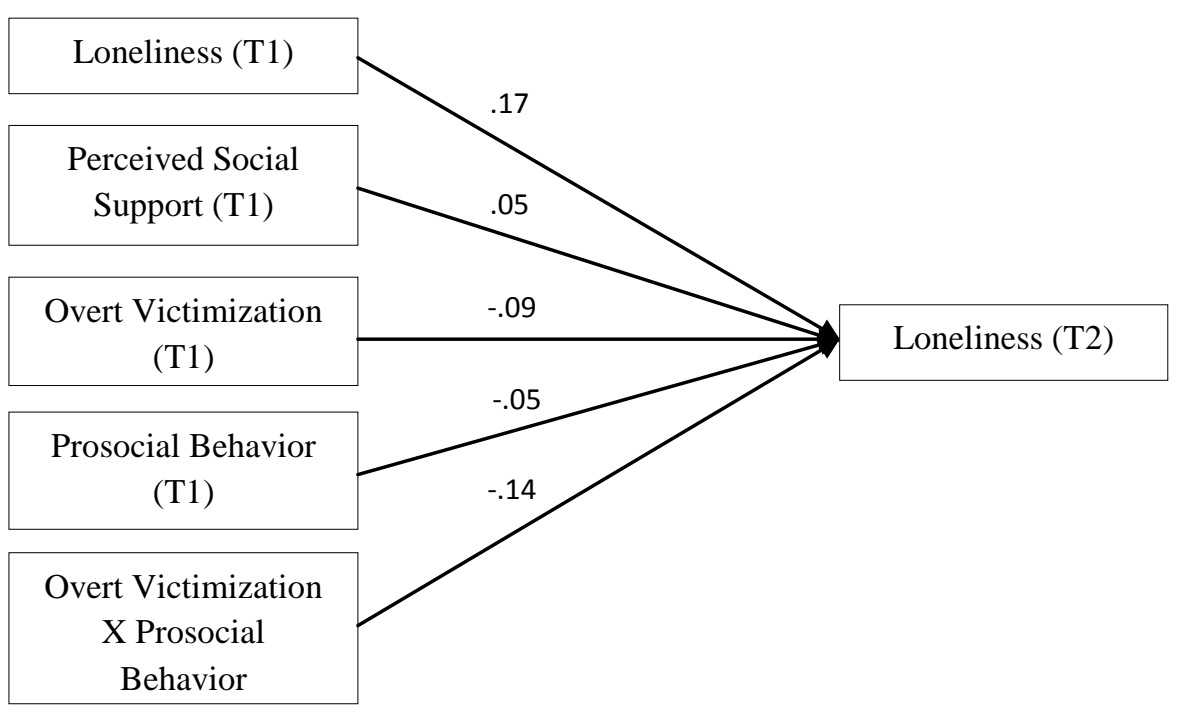

Figure 6. Overt Victimization X Prosocial Behavior moderation model for boys. Standardized regression coefficients are reported.

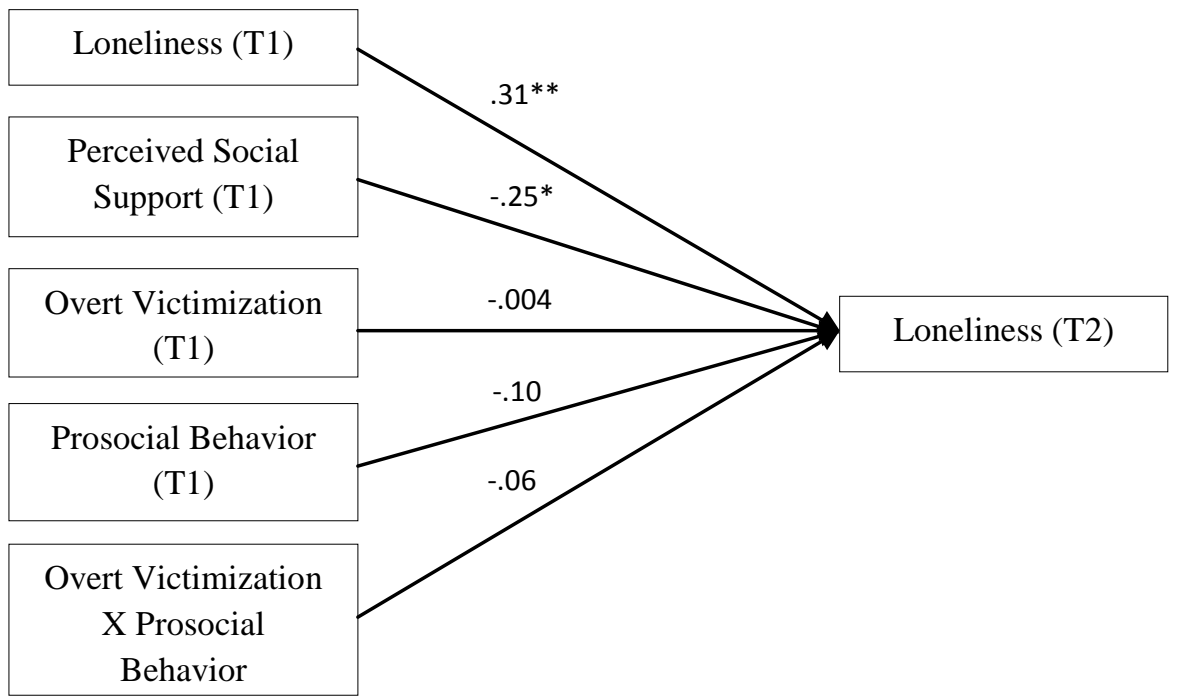

Figure 7. Overt Victimization X Prosocial Behavior moderation model for girls. Standardized regression coefficients are reported. 


\section{Further Findings}

In the relational victimization $\mathrm{x}$ prosocial behavior model for the girls (see figure 5), perceived social support was also significant within the model. This was not evident in the model for the boys (see figure 4). These findings suggest that the overall model examining both prosocial behaviors and perceived social support looks different for boys and girls.

\section{Follow-up Plots}

To visualize the nature of the significant interaction of relational victimization and prosocial behaviors on loneliness (T2) for the overall sample as well as separately for boys and girls, ANOVA plots were constructed using IBM SPSS Statistics Version 19.0 (2010). A new variable for prosocial behavior was created according to procedures outlined by Vitaro et al. (1991) which indicated that children with nomination scores half a standard deviation below the mean have significantly different effects from peer rejection (effects that may be parallel to those of victimized children in the current study) than children nominated a half standard deviation below the mean and above. Further, a relational victimization variable was created for children at low, moderate, and high levels of victimization using cut-offs for three equal groups.

For the overall sample, ANOVA plots of the results indicated that at high levels of relational victimization children engaged in higher levels of prosocial behavior had significantly lower levels of loneliness at time two (see Figure 8). That is, children who were nominated as highly relationally victimized and also nominated for having a prosocial behavioral tendency at levels at least one-half standard deviation below the mean and higher at time one had lower levels of loneliness over time than those highly 
relationally victimized with prosocial behavioral tendencies at levels at least one-half standard deviation below the mean. Further, these findings seemed to be unique for children in the high relational victimization category. Children in the moderate relational victimization category engaged in prosocial behaviors did not have significantly different levels of loneliness at time two from those victimized and not engaged in prosocial behaviors. Acting prosocially appears to serve as a protective factor for subsequent loneliness, but only for those children at high levels of relational victimization.

Similar findings were seen for both boys and girls (see Figures 9 and 10). Boys and girls who were nominated as highly relationally victimized and also nominated as engaged in prosocial behavior had significantly lower levels of loneliness at time two than those highly relationally victimized and had low levels of prosocial behavior.

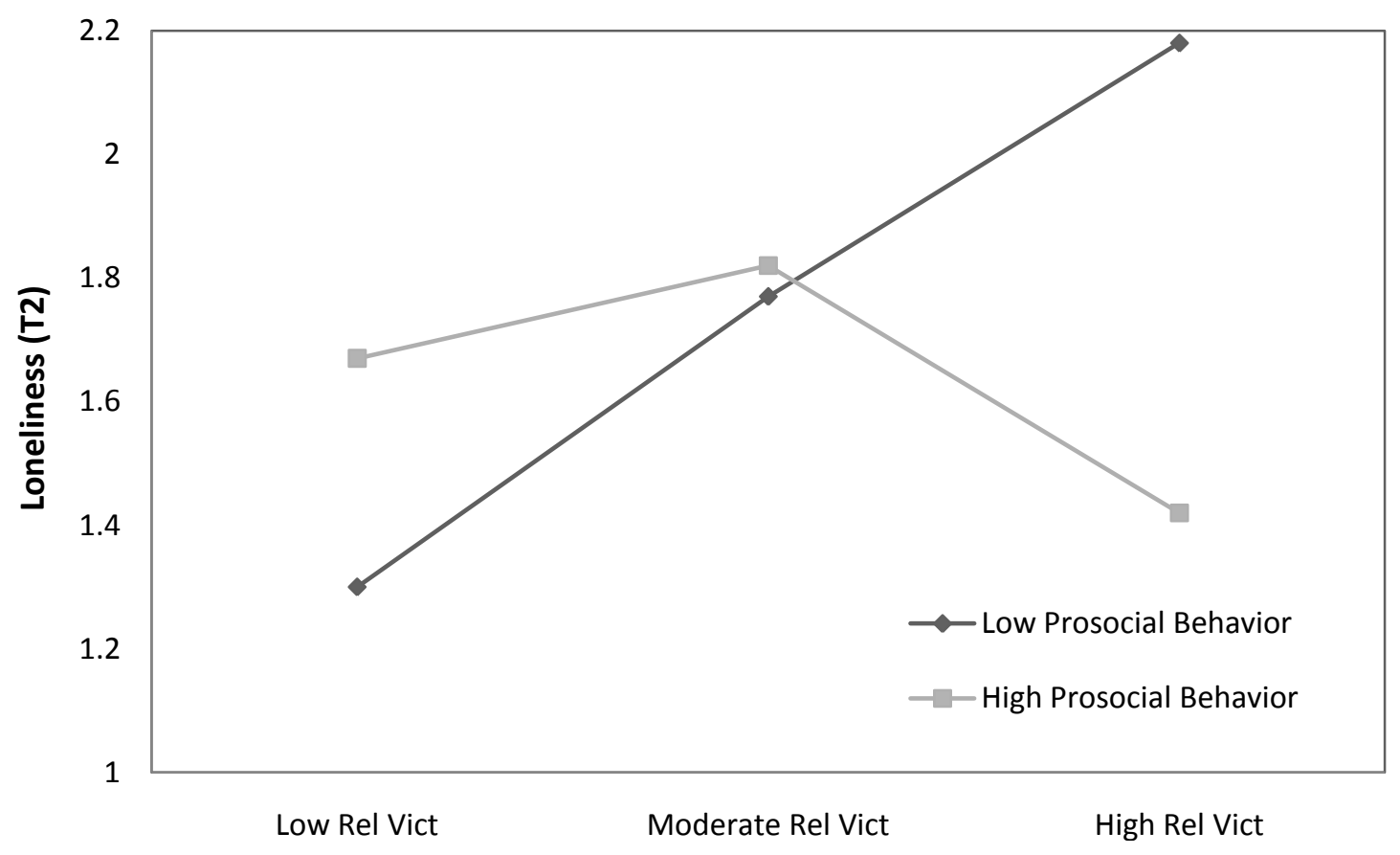

Figure 8. Plots of Relational Victimization X Prosocial Behavior on loneliness (T2). 


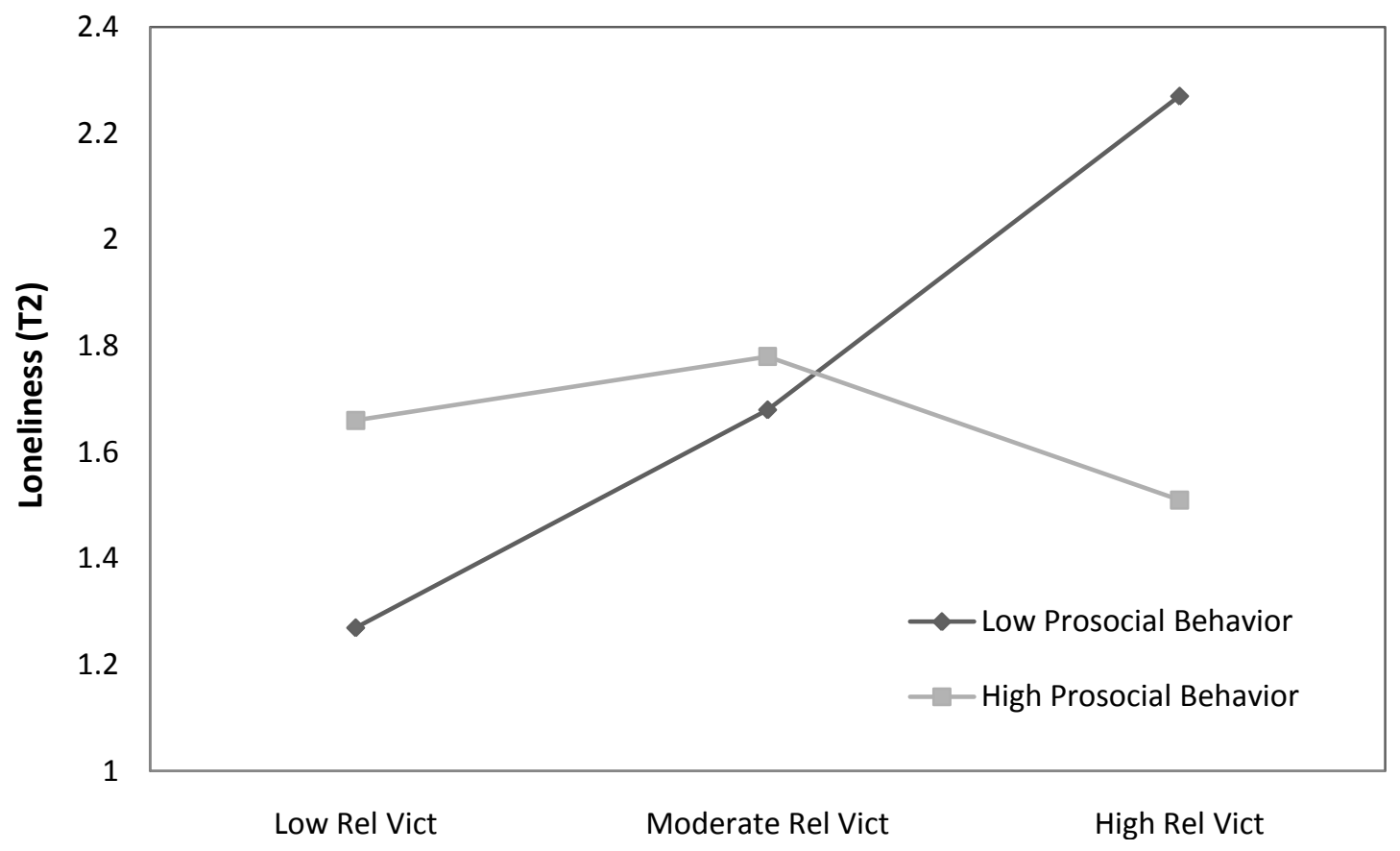

Figure 9. Plots of Relational Victimization X Prosocial Behavior on loneliness (T2) for boys.

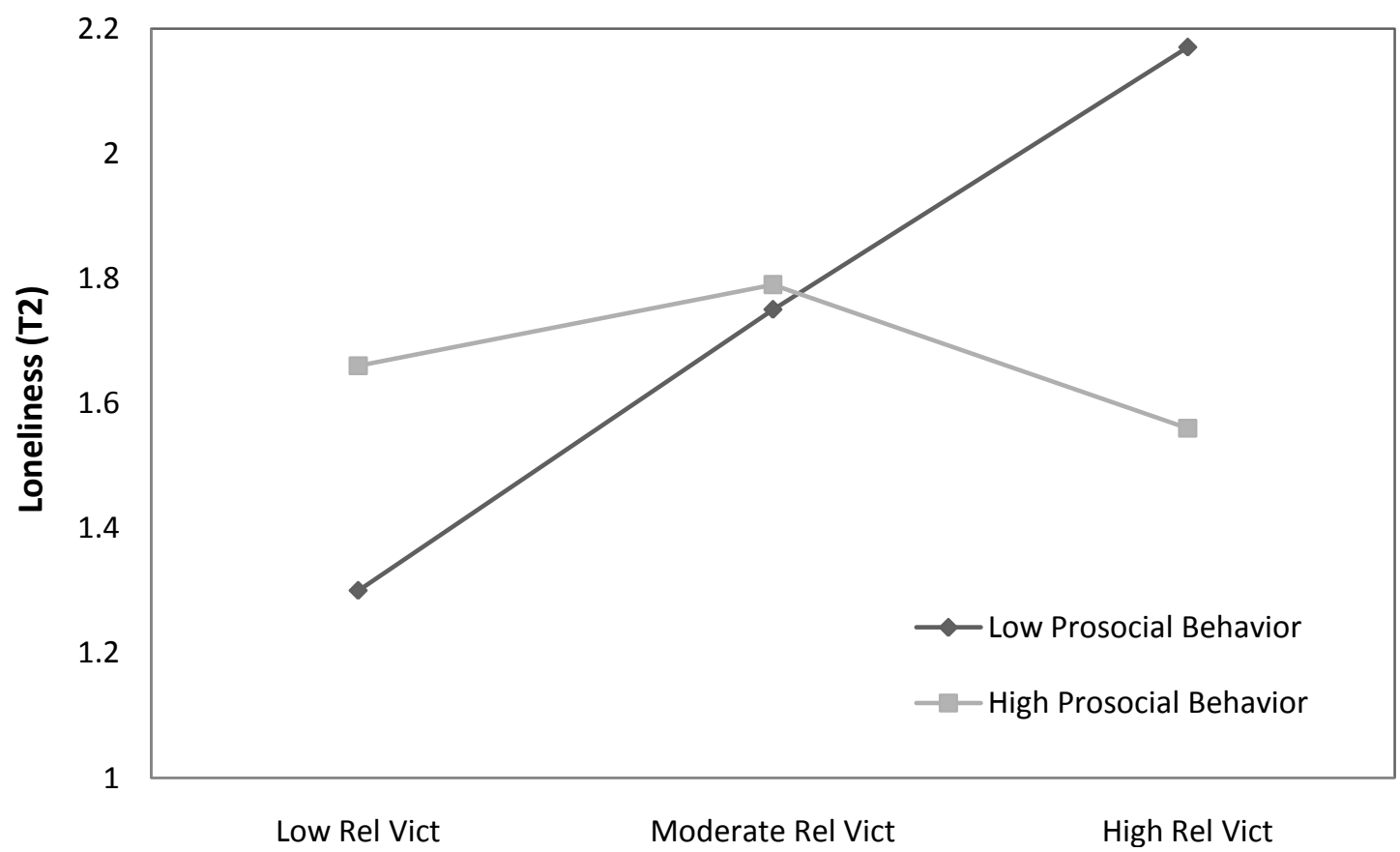

Figure 10. Plots of Relational Victimization X Prosocial Behavior on loneliness (T2) for girls. 


\section{Chapter V: Discussion}

Prior findings from peer relation studies have suggested that children's social behavior moderates the effects of victimization on adjustment (Kochenderfer-Ladd \& Ladd, 2001), yet examining potential effects of victimized children's positive behavioral tendencies has often been overlooked. Given findings from the research suggesting heterogeneity in children's responses to victimization, the primary goal of the current study was to examine children's prosocial behavior as a unique protective factor for those victimized by their peers. Prior evidence exists describing the protective function of prosocial peer support for victimized children's well-being, yet the current study illustrated the importance of acting prosocially as a protective factor against loneliness that was significant even after controlling for the influence of the child's prosocial peer support. Overall, the present findings were able to begin to address the lack of research regarding the longitudinal link between children's prosocial behaviors and victimization and their subsequent loneliness.

\section{Prosocial Behavior as a Moderator}

The results of this study confirmed that the effects of peer victimization on loneliness were moderated by a child's prosocial behavior. Findings indicated that the interaction term calculated between a child's prosocial behavior nominations and overall victimization nominations at time one were significantly related to the child's level of loneliness one year later. Further, follow up plots indicated this relationship was strongest amongst children who were highly victimized. Children at the highest levels of victimization who were also prosocial had significantly lower levels of loneliness at time two than children at moderate levels of victimization. These findings further support 
results from prior studies suggesting that the frequency of peer victimization places differential demands on a child's psychological resources and consequentially likely has an affect on a child's coping abilities (Kochenderfer-Ladd \& Ladd, 2001). For children at the highest levels of victimization, coping through acting prosocially rather than or in addition to relying on prosocial support from peers may be a more feasible coping strategy.

That is, coping strategies such as seeking social support from peers may be more viable for children at moderate levels of victimization as the stress on their social relationships may be at a lower level than those who are highly victimized. Thus, social support for moderately victimized children may provide the necessary protection from subsequent loneliness. Yet, for children at high levels of victimization, seeking social support may not be as effective of an option provided the level of stress victimization may create in their social relationships. For these children, personally engaging in prosocial behaviors appears to be a more feasible and sufficient coping strategy.

These findings lend more support to the idea that it is important to examine a child's prosocial behavioral tendency over and above their perceived social support. Prior research has often examined prosocial support from peers within the victimizationadjustment models (Martin \& Huebner, 2007), yet has continued to overlook children's own prosocial behaviors. Prior research findings have indicated that for victimized children, greater frequencies of prosocial support from peers operate as a protective factor for a child's emotional well-being. The current study added to the research examining potential protective factors for victims as children's prosocial behavioral tendencies moderated links from victimization and loneliness even when accounting for 
the role of prosocial support. These findings indicate the unique protective role of prosocial behaviors and the need to prioritize its development amongst children.

Researchers continue to report the benefits of these positive behaviors in other outcomes as well, indicating that prosocial experiences assist in facilitating the development of self-esteem, social skills, and interpersonal competences (Schwartz et al., 2000). The current findings provide additional evidence that, specifically for children at high levels of victimization, the skills associated with prosocial behaviors, at least in part, serve to buffer the experience of being victimized.

Further, it was suggested that these findings were consistent with the trend in prevention research to examine the role of a child's social assets in order to increase resiliency in the face of stress (Martin \& Huebner, 2007). Research models have often omitted the personal tools victims may need for resiliency against persistent victimization. The current study provides support for the contention that having prosocial behavioral tendencies while being victimized may serve as an important protective factor.

\section{Form of Victimization and Gender}

With respect to the form of victimization, it was hypothesized that prosocial behavior would be a stronger protective factor for children who were relationally victimized than for those overtly victimized. As suggested, the findings indicated that prosocial behavior moderated the relationship between relational victimization and loneliness, yet this interaction was not significant for the overt victimization models. Relational victimization, as previously suggested, is a form of victimization that has a higher level of socially related consequences such as social avoidance and lower social 
preference from peers (Putallaz et al., 2007). With the decrease in social preference and overall social support from peers that is distinct to this form of victimization, relationally victimized children may adapt by coping with victimization through other avenues, including acting prosocially. Overt victimization, on the other hand, is often more observable to peers when it occurs and may not elicit the same divisiveness as relational victimization at the social group level. Therefore, acting prosocially did not appear to serve the same protective role for overtly victimized children.

In exploring the current model for boys and girls, the path estimate for the interaction of prosocial behavior and relational victimization was stronger for boys than for girls. Further, the path estimate for perceived social support was significant for girls but not for boys. One possible explanation for this may be the items used to measure social support in the current study. In the current study, social support was measured by items such as, "How often do the kids in your class tell you you're good at things" or "How often do the kids in your class help you if someone is teasing you?", items that may not have tapped what many boys perceive to be social support from peers. Given that boys are more likely to develop larger peer networks (Hodges et al., 1999), their perception of social support may be more likely to take the form of group inclusion. Items measuring inclusion in group activities such as being included in a class activity or game may have more adequately assessed social support for boys. It is evident that further research examining both prosocial support and prosocial behavior in victimization-adjustment models for boys and girls is needed. 


\section{Limitations and Implications for Future Research}

Although this study presents significant findings regarding children's prosocial behaviors as a protective factor for victimization, prosocial behaviors as a coping strategy in direct response to victimization was not directly examined. Including questions asking children directly about the coping strategies applied when victimized would allow researchers to directly examine prosociality as a coping strategy. Further, the current study examined the relations of victimization and prosocial behavior on loneliness one year later. Examining these associations over a longer time span using a growth curve analysis may provide better estimates for longer term relations.

Although it is important to address how to stop victimization in the first place, current researchers and practitioners need to raise the inevitable question of what can be done for children who are being victimized. In light of the current study, it is evident that supporting the development of prosocial behaviors can serve as a protective factor for children undergoing higher levels of peer victimization. Unfortunately, although schools, teachers, and parents value positive social behaviors (most indicating a strong desire for students to be positive influences within the school and community), surprisingly little continues to be done within the schools to promote these behaviors in children at risk for victimization. Some educational stakeholders express concern with social behavior interventions as they may serve to distract from the arduous academic standards that must be met within the classroom (Malecki \& Elliot, 2003); a belief that may have stunted increased research on positive behavior development within the school systems (Feshbach \& Feshbach, 1987; Gresham \& Elliot, 1990; Wentzel, 1991). There is a large body of literature suggesting that children's social and emotional functioning are 
intimately adjoined in development, school adjustment, and academic performance (Bursuck \& Asher, 1986; Zins, Blodworth, Weissberg, \& Walberg, 2004) and our findings indicate how important the development of prosocial behaviors and the overall protective factor they may serve for victimized children may be to this linkage.

Further, our findings indicate that consideration of the form of victimization apparent is necessary. Intervention programs focused on providing victimized children with adequate social skills in order to prevent or reduce future victimization need to consider the form of victimization that is present. Findings from previous studies indicated that both boys and girls reported higher levels of relational victimization than overt victimization (Prinstein et al., 2001). Further, Coyne and colleagues (2006) found that youth (ages 11-15 years old) perceived relational aggression as more harmful than overt aggression. Although researchers are aware that both overt and relational victimization can be detrimental to a child's adjustment outcome, the current study suggests each form may require unique protective factors. It is evident that relational victimization can be detrimental to child's future adjustment outcomes, yet the current study provides support that developing a child's prosocial behaviors serves to protect against these negative outcomes. 


\section{References}

Aiken, L. S., \& West, S. G. (1991). Multiple regression: Testing and interpreting interactions. Thousand Oaks, CA: Sage Publications.

Asher, S. R., \& Paquette, J. A. (2003). Loneliness and peer relations in childhood. Current Directions in Psychological Science, 12, 75-78.

Baron, R. M., \& Kenny, D. A. (1986). The moderator-mediator distinction in social psychological research: Conceptual, strategic, and statistical consideration. Journal of Personality and Social Psychology, 51, 1173-1182.

Berndt, T. J., \& Ladd, G. (1989). Peer relationships in child development. New York: Wiley.

Bigelow, B.J., Tesson, G., \& Lewko, J.H. (1996). Learning the rules: The anatomy of children's relationships. New York: The Guilford Press.

Bjorkqvist, K., Lagerspetz, K. M. J., \& Kaukiainen, A. (1992). Do girls manipulate and boys fight? Developmental trends in regard to direct and indirect aggression. Aggressive Behavior, 18, 11 7- 127.

Block, J. H. (1983). Differential premises arising from differential socialization of the sexes: Some conjectures. Child Development, 54, 1335-1354.

Boivin, M., \& Hymel, S. (1997). Peer experiences and social self-perceptions: A sequential model. Developmental Psychology, 33, 135-145.

Boivin, M., Hymel, S., \& Bukowski, W. M. (1995). The roles of social withdrawal, peer rejection, and victimization by peers in predicting loneliness and depressed mood in childhood. Development and Psychopathology, 7, 765-785.

Boivin, M., Hymel, S. \& Hodges, E.V.E. (2001). Toward a process view of peer rejection and victimization. In J. Juvonen \& S. Graham (Eds.). Peer harassment in school: 
The plight of the vulnerable and victimized. (pp. 25-48). The Guildford Press: New York.

Brown, B. B. (1989). The role of peer groups in adolescents' adjustment to secondary school. In T.J. Berndt \& G.W. Ladd (Eds.), Peer relationships in child development (pp. 188-216). New York: Wiley.

Buhs, E., \& Ladd, G. (2001). Peer rejection as an antecedent of young children's school adjustment: An examination of mediating processes. Developmental Psychology, 37(4), 550-560. doi: 10.1037//OO12-1649.37.4.550

Buhs, E., Ladd, G., \& Herald, S. (2006). Peer exclusion and victimization: Processes that mediate the relation between peer group rejection and children's classroom engagement and achievement? Journal of Educational Psychology, 98, 1-13.

Bursuck, W. D., \& Asher, S. R. (1986). The relationship between social competence and achievement in elementary school children. Journal of Clinical Psychology, 15, $41-49$.

Carlo, G., Crockett, L. J., Randall, B. A., \& Roesch, S. C. (2007). A latent growth curve analysis of prosocial behavior among rural adolescents. Journal of Research on Adolescence, 17(2), 301-324. doi: 10.1111/j.1532-7795.2007.00524.x

Carlo, G., Hausmann, A., Christiansen, S., \& Randall, B.A. (2003). Sociocognitive and behavioral correlates of a measure of prosocial tendencies for adolescents. Journal of Early Adolescence, 23, 107-134.

Carlo, G., Raffaelli, M., Laible, D. J., \& Meyer, K. A. (1999). Why are girls less physically aggressive than boys? Personality and parenting mediators of physical aggression. Sex Roles, 40, 711-729. 
Carlo, G., Roesch, S. C., Knight, G. P., \& Koller, S. H. (2001). Between- or withinculture variation? Culture group as a moderator of the relations between individual differences and resource allocation preferences. Applied Developmental Psychology, 22, 559-579.

Coie, J., Terry, R., Lenox, K., Lochman, J., \& Hyman, C. (1995). Childhood peer rejection and aggression as predictors of stable patterns of adolescent disorder. Development and Psychopathology, 7, 697-713.

Coleman, P. K., \& Byrd, C. (2003). Interpersonal correlates of peer victimization in young adolescents. Journal of Youth and Adolescence, 32, 301-314.

Compas, B. E., Connor-Smith, J. K., Saltzman, A. H. T., \& Wadsworth, M. E. (2001). Coping with stress during childhood and adolescence: Problems, progress, and potential in theory and research. Psychological Bulletin, 127, 87-127. doi: $10.1037 / / 00332909.127 .1 .87$

Conrad, D., \& Hedin, D. (1982). The impact of experimental education on adolescent development. Child and Youth Servies, 4, 57-68.

Coyne, S., Archer, J., \& Eslea, M. (2006). "We're not friends anymore! Unless...”: The frequency of indirect, relational, and social aggression. Aggressive Behavior, 32, 294-307.

Crick, N. R. (1995). Relational aggression: The role of intent attributions, feelings of distress, and provocation type. Development and Psychopathology, 7, 313-322.

Crick, N. R., \& Bigbee, M. A. (1998). Relational and overt forms of peer victimization: A multiinformant approach. Journal of Consulting and Clinical Psychology, 6, 337-347. 
Crick, N. R., \& Dodge, K. A. (1996). Social information-processing mechanisms in reactive and proactive aggression. Child Development, 67, 993-1002.

Crick, N, R., \& Grotpeter, J. K. (1996). Children's treatment by peers: Victims of relational and overt aggression. Development and Psychopathology, 8, 367-380.

Crick, N. R., Grotpeter, J. K., \& Bigbee, M. A. (2002). Relationally and physically aggressive children's intent attributions and feelings of distress for relational and instrumental peer provocations. Child Development, 73, 1134-1142.

Egan, S. K., \& Perry, D. G. (1998). Does low self-regard invite victimization? Developmental Psychology, 34, 299-309.

Eisenberg, N. (1986). Altruistic emotion, cognition and behavior. Hillsdale, NJ: Erlbaum.

Eisenberg, N. (2003). Prosocial behavior, empathy, and sympathy. In M.H. Bornstein, L. Davidson, C.L.M. Keyes, \& K.A. Moore (Eds.) Well-Being: Positive development across the life course (pp. 253-265). Mahwayh, NJ: Earlbaum.

Eisenberg, N., \& Fabes, R.A. (1998). Prosocial development. In W. Damon, (Ed.), Handbook of child psychology: Social, emotional, and personality development (Vol. 3, pp. 701-778). New York: Wiley.

Eisenberg, N., Fabes, R. A., Bernzweig, J., Karbon, M., Poulin, R., \& Hanish, L. (1993). The relations of emotionality and regulation to preschoolers' social skills and sociometric status. Child Development, 64, 1418-1438.

Eisenberg N., Fabes, R. A., Guthrie, I. K., \& Reiser, M. (2000). Dispositional emotionality and regulation: Their role in predicting quality of social functioning. Journal of Personality and Social Psychology, 78, 136-157. 
Eisenberg, N., Fabes, R. A., Karbon, M., Murphy, B., \& Juhnke, C. (1996). The relations of dispositional prosocial behavior to emotionality, regulation, and social functioning. Child Development, 67, 974-992.

Eisenberg, N., Fabes, R. A., \& Spinrad, T. L. (2006). Prosocial development. In N. Eisenberg (Vol. Ed.), W. Damon \& R. M. Lerner (Series Eds.), Handbook of child psychology: Social, emotional, and personality development (Vol. 3, pp. 646718). New York: Wiley.

Eisenberg, N., Zhou, Q., \& Koller, S. (2001). Brazilian adolescents' prosocial moral judgment and behavior: Relations to sympathy, perspective taking, gender-role orientation, and demographic characteristics. Child Development, 72, 518-534.

Fabes, R.A., \& Eisenberg, N. (1992). Young children's coping with interpersonal anger. Child Development, 63, 116-128.

Fabes, R. A., Eisenberg, N., Karbon, M., Bernzweig, J., Speer, A.L., \& Carlo, G. (1994). Socialization of children's vicarious emotional responding and prosocial behavior: relations with mothers' perceptions of children's emotional reactivity. Developmental Psychology, 30, 44-55.

Feshbach, N.D., \& Feshbach, S. (1987). Affective processes and academic achievement. Child Development, 58, 1335-1347.

Fontaine, R. G., Yang, C., Burks, V. S., Dodge, K. A., Price, J. M., Pettit, G. S., et al. (2009). Loneliness as a partial mediator of the relation between low social preference in childhood and anxious/depressed symptoms in adolescence. Development and Psychopathology, 21, 479-491.

Gable, S. L. (2006). Approach and avoidance social motives and goals. Journal of Personality, 74, 176-222. doi: 10.1111/j.1467-6494.2005.00373.x 
Glyshaw, K., Cohen, L. H., \& Towbes, L. C. (1989). Coping strategies and psychological distress: Prospective analyses of early and middle adolescents. American Journal of Community Psychology, 17(5), 607-623.

Goldbaum, S., Craig, W. M., Pepler, D., \& Connolly, J. (2003). Developmental trajectories of victimization: Identifying risk and protective factors. Journal of Applied School Psychology, 19, 139-156.

Goodman K. L., \& Southam-Gerow, M. A. (2010). The regulating role of negative emotions in children's coping with peer rejection. Child Psychiatry Human Development, 41, 515-534. doi: 10.1007/s10578-010-0185-2

Greener, S. \& Crick, N.R. (1999). Normative beliefs about prosocial behavior in middle childhood: What does it mean to be nice? Social Development, 8(3), 349-363.

Gresham, F. M., \& Elliot, S. N. (1990). The social skills rating system. Circle Pine, MN: American Guidance Service.

Gross, J. J. (1998). The emerging field of emotion regulation: An integrative review. Review of General Psychology, 2, 271-299.

Grotpeter, J. K., \& Crick, N. R. (1996). Relational aggression, overt aggression, and friendship. Child Development, 62, 2328-2338.

Hanish, L. D., \& Guerra, N. G. (2002). A longitudinal analysis of patterns of adjustment following peer victimization. Development and Psychopathology, 14, 69-89.

Hodges, E.V., Boivin, M., Vitaro, F., \& Bukowski, W.M. (1999). The power of friendship: Protection against an escalating cycle of peer victimization. Developmental Psychology, 35, 94-101. 
Hoffman, M. L. (1982). Development of prosocial motivation: Empathy and guilt. In N. Eisenberg (Ed.), The development of prosocial behavior (pp. 281-338). New York: Academic Press.

Hoglund, W. L. (2005). Mediating effects of social-cognitive errors and skills for children experiencing peer relational, physical, and ethnic victimization. Dissertation Abstract International, 66 (5-A), 1637.

Holt, M. \& Espelage, D. (2003). A cluster analytic investigation of victimization profiles among high school students: Are profiles associated with differential psychological and educational outcomes? Journal of Applied School Psychology, 19, 81-98.

Hoover, J. H., Oliver, R. L., \& Hazler, R. J. (1992). Bullying: Perceptions of adolescent victimsin the Midwestern U.S.A. School Psychology International, 13, 5-16.

Hymel, S., Rubin, K. H., Rowden, L., \& LeMare, L. (1990). Children's peer relationships: Longitudinal prediction of internalizing and externalizing problems from middle to late childhood. Child Development, 61, 2004-2021.

Jackson, Y., \& Warren, J. (2000). Appraisal, social support, and life-events: Predicting outcome behavior in school-age children. Child Development, 71, 1441-1457.

Jobe-Shields, L. J., Cohen, R., \& Parra, G. R. (2011). Patterns of change in children's loneliness: Trajectories from third through fifth grades. Merrill-Palmer Quarterly, $51,25-47$.

Khatri, P., Kupersmidt, J. B., \& Patterson, C. (2000). Aggression and peer victimization as predictors of self-reported behavioral and emotional adjustment. Aggressive Behavior, 26, 345-358. 
Kochenderfer-Ladd, B. (2004). The role of emotions in adaptive and maladaptive coping with peer victimization. Social Development, 3, 329-349.

Kochenderfer, B., \& Ladd, G. (1996). Peer victimization: Cause or consequence of school maladjustment? Child Development, 67, 1301-1317.

Kochenderfer, B., \& Ladd, G. (1997). Victimized children's responses to peers' aggression: Behaviors associated with reduced versus continued victimization. Development and Psychopathology, 9, 59-73.

Kochenderfer-Ladd, B., \& Ladd, G. (2001). Variations in peer victimization: Relations to children's maladjustment. In J. Juvonen \& S. Graham (Eds.). Peer harassment in school: The plight of the vulnerable and victimized. (pp. 25-48). The Guildford Press: New York.

Kochenderfer-Ladd, B., \& Skinner, K. (2002). Children's coping strategies: Moderators of the effects of peer victimization?. Developmental Psychology, 38(2), 267-278.

Kochenderfer-Ladd, B., \& Wardrop, J. L. (2001). Chronicity and instability of children's peer victimization experiences as predictors of loneliness and social satisfaction trajectories. Child Development, 72, 134- 151.

Langrock, A. M., Compas, B. E., Keller, G., Merchant, M. J., \& Copeland, M. E. (2002). Coping with the stress of parental depression: parents' reports of children's coping, emotional, and behavioral problems. Journal of Clinical Child and Adolescent Psychology, 31, 312-324, doi:10.1207/S15374424JCCP3103_03.

Lazarus, R.S., (1991). Emotion and adaptation. In Pervin, L. A. (Ed.). Handbook of personality: Theory and research, (pp. 609-637), New York: Guilford. 
Lazarus, R., \& Folkman, S. (1984). Stress, appraisal, and coping. New York: Springer Publishing Company.

Leadbeater, B., Kuperminc, G., Blatt, S., \& Hertzog, C. (1999). A multivariate model of gender differences in adolescents' internalizing and externalizing problems. Developmental Psychology, 35(5), 1268-1282.

Lengua, L.J., \& Long, A.C. (2002). The role of emotionality and self-regulation in the appraisal-coping process: Tests of direct and moderating effects. Journal of Applied Developmental Psychology, 23, 471-493.

Malecki, C. K., \& Elliot, S. N. (2003). Children's social behaviors as predictors of academic achievement: A longitudial analysis. School Psychology Quarterly, 17, 1-23. doi: 10.1521/scpq.17.1.1.19902

Martin, K. M. \& Huebner, E. S. (2007). Peer victimization and prosocial experiences and emotional well-being of middle school students. Psychology in the Schools, 44, 199-208.

McLaughlin, K.A., Hatzenbuehler, M.L., \& Hilt, L.M. (2009). Emotion dysregulation as a mechanism linking peer victimization to internalizing symptoms in adolescents. Journal of Consulting and Clinical Psychology, 77, 894-904.

Miller, P., Danaher, D., \& Forbes, D. (1986). Sex-related strategies for coping with interpersonal conflict in children aged five and seven. Developmental Psychology, $22,543-548$.

Nishina, A., Juvonen, J., \& Witkow, M. R. (2005). Sticks and stones may break my bones, but names will make me feel sick: The psychosocial, somatic, and scholastic consequences of peer harassment. Journal or Clinical Child and Adolescent Psychology, 34, 37-48. 
Olweaus, D. (1993). Victimization by peers: Antecedents and long-term outcomes. In K. H. Rubin \& J. B. Asendorpf (Eds.). Social withdrawal, inhibition and shyness in childhood (pp. 315-341). Hillsdale, NJ: Erlbaum.

Ostrov, J. M., \& Keating, C. F. (2004). Gender differences in preschool aggression during free play and structured interactions: An observational study. Social Development, 13, 255-277.

Paquette, J. A., \& Underwood, M. K. (1999). Gender differences in young adolescents' experiences of peer victimization: Social and physical aggression. Merrill-Palmer Quarterly, 45, 242-266.

Parkhurst, J. T., \& Asher, S. R. (1992). Peer rejection in middle school: Subgroup differences in behavior, loneliness, and interpersonal concerns. Developmental Psychology, 28, 231-241.

Paul, J. J., \& Cillessen, A. H. N. (2003). Dynamics of peer victimization in early adolescence: Results from a four-year longitudinal study. Journal of Applied School Psychology, 19, 25-43.

Prinstein, M. J., Boergers, J., \& Vernberg, E. M. (2001). Overt and relational aggression in adolescents: Social-psychological adjustment of aggressors and victims. Journal of Clinical Child Psychology, 30, 479-491.

Prinstein M. J., \& Cillessen A. H. N. (2003). Forms and functions of adolescent peer aggression associated with high levels of peer status. Merrill-Palmer Quarterly, 49, 310-342. 
Putallaz, M., Grimes, C. L., Foster, K. J., Kupersmidt, J., \& Coie, J. D. (2007) Overt and relational aggression and victimization: Multiple perspectives within the school setting. Journal of School Psychology, 45, 459-586.

Roecker Phelps, C.E. (2001). Children's responses to overt and relational aggression. Journal of Clinical Child Psychology, 30, 240-252.

Rubin, K. H., Bukowski, W. M., \& Parker, J. G. (2006). Peer interactions, relationships, and groups. In N. Eisenberg, W. Damon, \& R. M. Lerner (Eds.), Handbook of child psychology: Vol. 3. Social, emotional, and personality development (6th ed., pp. 571-645). Hoboken, NJ: Wiley.

Ruble, D.N., \& Martin, C.L. (1998). Gender development. In W. Damon (Ed.), Handbook of child psychology: Vol. 3 (pp. 933-1016). New York: Wiley.

Sandler, I. N., Braver, S., \& Gensheimer, L. (2000). Stress: Theory, research, and action. In J. Rappaport \& E. Seidman (Eds.), Handbook of community psychology (pp. 187-213). New York: Kluwer.

Santiago-Rivera, A.L., Bernstein, B., \& Gard, T. (1995). The importance of achievement and the appraisal of stressful events as predictors of coping. Journal of College Student Development, 36(4), 374-383.

Scales, P. C., Benson, P. L., Leffert, N., \& Blyth, D. A. (2000). Contribution of developmental assets to the prediction of thriving among adolescents. Applied Developmental Science, 4, 27-46.

Schwartz, D., Dodge, K. A., \& Coie, J. D. (1993). The emergence of chronic peer victimization in boys' play groups. Child Development, 64, 1755-1772. 
Schwartz, D., Dodge, K. A., Pettit, G. S., \& Bates, J. E. (2000). Friendship as a moderating factor in the pathway between early harsh home environment and later victimization in the peer group. Developmental Psychology, 36, 646-662.

Shonert-Reichl, K. A. (1999). Relations of peer acceptance, friendship adjustment, and social behavior to moral reasoning during early adolescence. The Journal of Early Adolescence, 19 (2), 249-279. doi: 10.1177/0272431699019002006.

Smith, C.L., Eisenberg, N., Spinrad, T.L., Chassin, L., Morris, A.M., Kupfer, A, et al. (2006). Children's coping strategies and coping efficacy: Relations to parent socialization, child adjustment, and familial alcoholism. Development and Psychopathology, 18, 445-469.

Smith, P.K., Shu, S., \& Madsen, K. (2001). Characteristics of victims of school bullying: Developmental changes in coping strategies and skills. In J. Juvonen \& S. Graham (Eds.), Peer harassment in school: The plight of the vulnerable and victimized (pp. 332-351). London: Guilford Press.

Southam-Gerow, M. A., \& Kendall, P. C. (2000). A preliminary study of the emotion understanding of youth referred for treatment of anxiety disorders. Journal of Clinical Child Psychology, 29, 319-327.

Storch, E. A., \& Brassard, M. R. (2003). The relationship of peer victimization to social anxiety and loneliness in adolescence. Child Study Journal, 33, 1-18.

Storch, E. A., \& Masia, C. L. (2001). Peer victimization and social anxiety and distress in adolscence. In M. Prinstein (Chair), Peer relationships, social anxiety, and developmental psychopathology. Symposium presented at the annual meeting of the Association for the Advancement of Behavioural Therapy, Philadelphia, PA, November. 
Troop-Gordon, W., \& Ladd, G. W. (2005). Trajectories of peer victimization and perceptions of the self and schoolmates: Precursors to psychological and school maladjustment. Child Development, 76, 1072-1091.

Underwood, M., Scott, B., Galperin, M., Bjornstad, G., \& Sexton, A. (2004). An observational study of social exclusion under varied conditions: Gender and developmental differences. Child Development, 75, 1538-1555.

Vaillancourt, T., Brendgen, M., Boivin, M., \& Tremblay, R. E. (2003). A longitudinal confirmitory factor analysis of indirect and physical aggression: Evidence of two factors over time? Child Development, 74, 1628-1638.

Vernberg, E. M., Jacobs, A. K., \& Hershberger, S. L. (1999). Peer victimization and attitudes about violence during early adolescence. Journal of Clinical Child Psychology, 28(3), 386-395.

Visconti, K. J., \& Troop-Gordon, W. (2010). Prospective relations between children's behavioral responses to peer victimization and their socioemotional adjustment. Journal of Applied Developmental Psychology, 31, 261-272.

Vitaro, F., Gagnon, C., \& Tremblay, R. E. (1990). Predicting stable peer rejection from kindergarten to grade one. Journal of Clinical Child Psychology, 257-264.

Wadsworth, M. E., \& Compas, B. E. (2002). Coping with family conflict and economic strain: The adolescent perspective. Journal of Research on Adolescent Development, 12, 243-274. doi: 10.1111/1532-7795.00033

Warden, D., \& Mackinnon, S. (2003). Prosocial children, bullies and victims: An investigation of their sociometric status, empathy and social problem-solving 
strategies. British Journal of Developmental Psychology, 21 (3), 367-385. doi:

$10.1348 / 026151003322277757$

Wentzel, K. R. (1991). Relations between social competence and academic achievement In early adolescence. Child Development, 62, 1066-1078.

Wentzel, K. R., \& Asher, S. R. (1995). The academic lives of neglected, rejected, popular, and controversial children. Child Development, 66, 754-763.

Zimmer-Gembeck, M. J., Geiger, T. C., Crick, N.R. (2005). Relational and physical aggression, prosocial behavior, and peer relations: Gender moderation and bidirectional associations. Journal of Early Adolescence, 25, 421-452.

Zins, J., Bloodworth, M., Weissberg, R., \& Walberg, H. (2004). The scientific base linking social and emotional learning to school success. In J. Zins, R. Weissberg, M. Wang, \& H.J. Walberg (Eds.). Building academic success on social and emotional learning: What does the research say? (pp. 1-22). New York: Teachers Press, Columbia University. 


\section{Appendix A}

\section{Peer Reported Relational Victimization}

Circle the people who other kids often leave out of conversations, games, or activities. Circle the people who other kids gossip about or say bad things about behind their backs. 
Appendix B

\section{Peer Reported Overt Victimization}

Circle the people who get hit, pushed, or kicked by other kids.

Circle the people who get called bad names (teased, insulted) by other kids. 
Appendix C

Peer Reported Prosocial Behavior

Circle the people who help other kids the most.

Circle the people who are friendly towards lots of other kids. 


\section{Appendix D}

\section{What Things are Like}

For each of the statements below, think about the past week. Read each statement and decide how often you felt the way described during the past week.

$\begin{array}{lcccc}\text { Almost } & \text { A } & \text { Some- } & \text { A } & \text { Almost } \\ \text { Never } & \text { Little times } & \text { Lot } & \text { Always }\end{array}$

\section{How often...}

1) How often do the kids in your class

tell you you're good at things................. $\quad 1 \quad 4 \quad 3 \quad 4 \quad 5$

2) How often do the kids in your class help

you if someone is teasing you?.......................... $\quad 1 \quad 4 \quad 2 \quad 3 \quad 4 \quad 5$

3) How often do the kids in your class explain the directions

for an assignment if you don't understand them?.. 1

4) How often do the kids in your class

cheer you up if you feel sad?..............................

5) How often do the kids in your class share things

like paper, books, or pencils with you?................

6) How often do the kids in your class help

you if other kids are picking on you?..................

$\begin{array}{lllll}1 & 2 & 3 & 4 & 5\end{array}$




\title{
Appendix E
}

\begin{abstract}
About School
Now we're going to ask some questions about how you feel and what you think about school. For each question, circle only one number. Choose 1 for almost never, 2 for a little, 3 for sometimes, 4 for a lot, and 5 for almost always.
\end{abstract}

Please fill out the following section to reflect your views, even if other people might not agree.

Please only circle one number per question.

1) Is school enjoyable?

**2) Is school a lonely place for you?

$\begin{array}{lllll}1 & 2 & 3 & 4 & 5 \\ 1 & 2 & 3 & 4 & 5 \\ 1 & 2 & 3 & 4 & 5 \\ & & & & \\ 1 & 2 & 3 & 4 & 5 \\ 1 & 2 & 3 & 4 & 5 \\ 1 & 2 & 3 & 4 & 5 \\ 1 & 2 & 3 & 4 & 5 \\ 1 & 2 & 3 & 4 & 5 \\ 1 & 2 & 3 & 4 & 5\end{array}$

**10) I feel sad and alone at school. How often does this happen?

$\begin{array}{lllll}1 & 2 & 3 & 4 & 5\end{array}$

11) Do you feel better when it's time to go home from school?

$\begin{array}{lllll}1 & 2 & 3 & 4 & 5\end{array}$

12) Do you ask your parents to let you stay home from school?.

**13) I feel left out of things at school.

How often does this happen?.

14) Do you wish you didn't have to go to school?.....

15) Do you like going to school?.

**16) I feel lonely at school. How often does this happen?

$\begin{array}{lllll}1 & 2 & 3 & 4 & 5 \\ 1 & 2 & 3 & 4 & 5 \\ 1 & 2 & 3 & 4 & 5 \\ 1 & 2 & 3 & 4 & 5\end{array}$

**Items Included in Study 